\title{
Prenatal Development of Layer-Specific Local Circuits in Primary Visual Cortex of the Macaque Monkey
}

\author{
Edward M. Callaway \\ Systems Neurobiology Laboratory, The Salk Institute for Biological Studies, La Jolla, California 92037
}

Previous studies have demonstrated that axonal arbors specific for the four main cortical layers - 2/3, 4, 5, and 6-develop precisely from the outset using activity-independent cues. In macaque primary visual cortex (V1), layer $2 / 3$ is subdivided into layers named $2 / 3 \mathrm{~A}, 3 \mathrm{~B}, 4 \mathrm{~A}$, and $4 \mathrm{~B}$, and layer 4 is subdivided into $4 \mathrm{C} \alpha$ and $4 \mathrm{C} \beta$. Individual neurons in V1 of mature macaques have axonal arbors that are highly specific for these sublayers. We have studied the prenatal development of laminar and sublaminar specificity of local circuits in macaque V1. Two-hundred thirty-eight neurons were labeled intracellularly in living brain slices prepared from V1 of five prenatal macaque monkeys aged 100 to $145 \mathrm{~d}$ postconception (E100-E145). Axonal and dendritic arbors of labeled neurons were reconstructed to assess their relationships to the cortical layers. We find that developing spiny neurons in layers 2-4B and layer 5 specifically target superficial and deep layers without forming "incorrect" branches in layer 4C. Similarly, layer 6 pyramidal neurons that target layer $4 \mathrm{C}$ do not form "incorrect" branches in layer 5 . These results indicate that specific projections to the main cortical layers develop with a high degree of selectivity, as in other species. However, the development of sublayerspecific projections was not always precise from the outset. Unlike postnatal animals, axons of some prenatal layer $4 \mathrm{C} \beta$ spiny neurons branch in layer 4B. At similar ages, many pyramidal neurons in the upper half of layer 6 have axonal branches in layer $4 \mathrm{C} \alpha$ as well as $4 \mathrm{C} \beta$; these projections are specific for $4 \mathrm{C} \beta$ in more mature animals. Also, there is similar "exuberance" in axonal arbors of other layer 6 cell types. Transient projections were also observed in the subplate and to the white matter for cells from all layers, except $4 \mathrm{C} \beta$. These observations indicate that at least some sublayer-specific projections emerge by elimination of exuberant axonal branches and suggest that they may use activity-dependent mechanisms to identify "correct" target layers. Such cues could be provided by laminar differences in the patterns of spontaneous prenatal activity in the retino-geniculo-cortical network.

Key words: development; local circuits; primate; macaque; visual cortex; V1; area 17; striate cortex
One of the most striking features of the cerebral cortex is its laminar organization. Local cortical circuits, cortico-cortical connections, and interconnections with subcortical structures are all layer-specific. The precise organization of these connections dictates adult cortical function. Thus, understanding the mechanisms that give rise to the development of layer-specific connections is crucial to understanding the factors that determine cortical function.

Previous studies have shown that layer-specific connections in cerebral cortex can develop with a high degree of specificity from the outset, using activity-independent cues such as molecular markers (for review, see Katz and Callaway, 1992; Bolz et al., 1996). These studies have focused on axons that selectively target one or more of the four main cortical layers: $2 / 3,4,5$, or 6 . For example, consider the following: developing layer $2 / 3$ pyramidal neurons in cat striate cortex selectively target layers $2 / 3$ and 5 , avoiding layer 4 (Katz, 1991); LGN axons selectively target layers 4 and 6 of cortical slices in vitro (Yamamoto et al., 1989; Blakemore and Molnar, 1990; Bolz et al., 1992); and layer 6 pyramidal

Received Oct. 1, 1997; revised Dec. 1, 1997; accepted Dec. 4, 1997.

This work was supported by National Institutes of Health Grant EY10742. I thank Lori Greiner for assistance with animals, Cynthia Hutt for ultrasounds, Drs. Curt Freed and James Stevens for performing Cesarean sections, Atomu Sawatari and Dr. Anne Wiser for assistance labeling neurons, Wendy Freeman, Stephan Kempiak, and Melissa McCabe for camera lucida reconstructions, Sumit Dua for assistance in preparing figures, and Jami Dantzker and Dr. Kimberley McCallister for very helpful comments on this manuscript.

Correspondence should be addressed to Edward M. Callaway, The Salk Institute, SNL-C, 10010 North Torrey Pines Road, La Jolla, CA 92037.

Copyright (C) 1998 Society for Neuroscience $0270-6474 / 98 / 181505-23 \$ 05.00 / 0$ neurons in ferret striate cortex selectively target layers $2 / 3$ and 4, avoiding layer 5, both in vivo (Callaway and Lieber, 1996) and in in vitro slice cultures (Dantzker and Callaway, 1997).

These four cortical layers are present in all cortical areas (see, for example, Brodmann, 1909). However, in primate primary visual cortex, there are additional layers. Using the numbering scheme of Brodmann (1909), layers 2-4B of V1 in the macaque monkey are equivalent to layer $2 / 3$ of other species, and layer $4 \mathrm{C}$ to layer 4 (Hassler, 1967; Casagrande and Kaas, 1994). These layers are subdivided further: layers $2-4 \mathrm{~B}$ into layers $2 / 3 \mathrm{~A}, 3 \mathrm{~B}$, $4 \mathrm{~A}$, and $4 \mathrm{~B}$; and layer $4 \mathrm{C}$ into layers $4 \mathrm{C} \alpha$ and $4 \mathrm{C} \beta$. In addition to the cytoarchitectonic distinctions between layers, LGN afferents and local circuits within primate V1 are highly specific for these subdivisions (for review, see Lund, 1988; Callaway, 1998). Most notably, spiny stellate neurons in layer $4 \mathrm{C} \beta$ specifically target layers $4 \mathrm{~A}$ and $3 \mathrm{~B}$ but do not branch in the intervening layer $4 \mathrm{~B}$, and many layer 6 pyramidal neurons have axonal and dendritic arbors that are specific for layer $4 \mathrm{C} \alpha$, layer $4 \mathrm{C} \beta$, or even the middle of layer 4C (Wiser and Callaway, 1996). A previous Golgi study concluded that sublayer-specific connections in macaque V1 are generated precisely from the outset (Lund et al., 1977), but at that time the adult organization of V1 local circuits was not well understood (cf. Wiser and Callaway, 1996).

We were particularly interested, therefore, in how connections that are specific for the sublayers in macaque V1 develop. Are axonal arbors formed specifically in the correct sublayers from the outset, as they are for the four main layers in other species? Or is there initial exuberance followed by elimination of axonal 
branches in incorrect layers? The answers to these questions have important implications for a number of issues. For example, do the "extra" layers in primate V1 arise because neuronal precursors give rise to cortical neurons with unique laminar identities not present in other cortical areas? Or do the sublayers emerge from the same cell types and distributions as in the main layers, but under the regulation of epigenetic influences such as patterned neuronal activity? Do different cell types within a single cortical layer emerge from an initially uniform, equipotential population of cells that differentiate in response to different environmental influences (e.g., patterned neural activity), or are their fates predetermined?

To follow the emergence of laminar and sublaminar specificity of local circuits, we have intracellularly labeled and analyzed the axonal and dendritic arbors of 238 neurons in living brain slices from the primary visual cortex of five prenatal macaque monkeys, aged 100-145 d postconception (E100-E145, birth is typically at $\sim$ E165). We find that developing axonal arbors distinguish precisely between the four main layers $(2-4 \mathrm{~B}, 4 \mathrm{C}, 5$, and 6$)$ from the outset. However, specificity for sublayers is often imprecise. Axonal arbors initially arborize in "incorrect" layers, and the incorrect projections are then eliminated.

\section{MATERIALS AND METHODS}

Individual neurons were intracellularly labeled with biocytin in living coronal slices of V1 from 5 prenatal macaque monkeys (4 Macaca radiata, $1 \mathrm{M}$. nemestrina) of estimated gestational ages from E100 to E145 (see below, gestation is typically $165 \mathrm{~d}$ ). The methods used for slice preparation, cell labeling, tissue staining, and analysis of neurons were essentially identical to those described previously (Callaway and Wiser, 1996; Wiser and Callaway, 1996), except that brain tissue was collected from prenatal animals after Cesarean delivery.

Neurons were labeled during whole-cell recording with patch electrodes containing $2 \%$ biocytin. After labeling of neurons, brain slices were fixed, sectioned, and double-stained for biocytin and cytochrome oxidase $(\mathrm{CO})$. Axonal and dendritic arbors were reconstructed by camera lucida drawing. Only cells in which all axonal branches could be clearly followed until they either ended or left the plane of the slice were included in our analyses. Cells whose axons became faint or had branchpoints that were difficult to detect were excluded.

Each neuron was investigated to determine whether its main descending axon projected to the white matter. When the axon could be seen entering the white matter, the cell was scored as a projection neuron. Neurons were scored as nonprojecting only if the descending axon clearly ended within the plane of the slice. If the descending axon left the plane of the slice before entering the white matter, the cell was scored as ambiguous.

The depth of the cell body of each layer 6 pyramidal neuron within layer 6 was calculated by measuring the distance between the base of the cell body and the layer $5 /$ layer 6 border, dividing this distance by the whole depth of layer 6 , and multiplying this ratio by 100 . We defined "superficial" as a depth inferior or equal to $40 \%$, "middle" as between 40 and $60 \%$, and "deep" as superior or equal to $60 \%$. This is identical to the method used by Wiser and Callaway (1996).

Unlike postnatal tissue, CO staining was not always a reliable indicator of laminar boundaries in prenatal animals, and it does not reveal the precise location of the border between layers $4 \mathrm{C} \alpha$ and $4 \mathrm{C} \beta$ at any age. Therefore, after camera lucida reconstruction of axonal and dendritic arbors, coverslips were removed from the tissue and it was stained for Nissl substance with thionin. The thionin stain obscured some of the finer processes of biocytin-labeled neurons, but because they had already been reconstructed, the visible processes could be aligned with the camera lucida drawings. Laminar boundaries identified by CO staining were then verified based on the Nissl stain, and borders that were not detectable or were ambiguous were added.

The laminar pattern of $\mathrm{CO}$ staining in the oldest animal from our study (E145) was similar to that reported previously for newborn animals (Kennedy et al., 1985). The darkest CO stain is found in layer 4C, but unlike adult animals, in which layer $4 \mathrm{C}$ usually stains uniformly, there is a light zone in upper layer $4 \mathrm{C} \beta$. Thus, layer $4 \mathrm{C} \alpha$ is dark and there is a thin dark band at the bottom of layer $4 \mathrm{C} \beta$; these zones are separated by the lighter-staining region. We also did not detect $\mathrm{CO}$ "blobs" in any of our prenatal tissue (see, for example, Horton, 1984). Otherwise, the laminar pattern at E145 was similar to that in mature animals, with layers $4 \mathrm{~A}$ and 6 staining relatively dark and layers $2 / 3,4 \mathrm{~B}$, and 5 staining light. At E135 the staining is similar to that at E145, except that the dark band at the bottom of layer $4 \mathrm{C} \beta$ extends into the top of layer 5 as identified by Nissl stain. This trend continues in the next youngest animal (E122), in which relatively dark staining extends well into layer 5. At ages less than E122 (E100, E108), layer 4A was not detectable with the CO stain. Also, although layers $4 \mathrm{C}$ and 6 tended to be darker than other layers at E100 and E108, these differences were not always reliable indicators of the laminar boundaries as revealed by Nissl stain. Therefore, at these ages, laminar boundaries were defined solely by the Nissl staining.

Estimation of gestational age. The ages of fetuses were estimated from ultrasonic measurements of crown-to-rump length (CRL) early in gestation or biparietal distance (BPD) at later ages. BPD was also measured directly at the time of Cesarean delivery. The values were then compared with published values of similar measurements from timed pregnancies (Tarantal and Hendrickx, 1988; Conrad et al., 1995). These studies report that CRL is the most reliable indicator of gestational age at 20-60 d postconception. The measures are also remarkably similar for three different species of macaque monkey $-M$. nemestrina, $M$. fascicularis, and M. mulatta - despite differences in size at birth (Tarantal and Hendrickx, 1988). Thus, the values are also likely to be applicable to $M$. radiata. CRL measurements at 20-60 d of gestation were available for all $4 M$. radiata used in this study. These animals had estimated ages of E100, E108, E122, and E135 at the time of delivery. For 1 of these animals (E108), the CRL measure was very early $(\sim$ E20), and we were concerned, therefore, about the reliability of the measurement. Thus, an additional ultrasound was done at an estimated gestational age of E81. Because BPD is a reliable indicator of gestational age after E60 (Tarantal and Hendrickx, 1988; Conrad et al., 1995), this value was used and the age estimate varied from the early CRL measure by $5 \mathrm{~d}$. Age estimates from BPD at delivery were also always in good agreement with the estimates from CRL (within 1-5 d). For one animal (also the only $M$. nemestrina), no ultrasound measures were available. The age of this fetus was estimated solely from the BPD at the time of delivery. The estimated age of this animal (E145) is based on published measures from the same species (Conrad et al., 1995), because differences between species are evident at this age (Tarantal and Hendrickx, 1988).

\section{RESULTS}

Two-hundred thirty-eight neurons were labeled intracellularly in coronal brain slices from 5 prenatal macaque monkeys, and the laminar specificities of their axonal and dendritic arbors were analyzed. The estimated ages of the animals used were E100, E108, E122, E135, and E145 (see Materials and Methods). The numbers of cells labeled in each cortical layer from each of these animals are indicated in Table 1 . The values indicate the total number of spiny (presumed excitatory) neurons that met our criteria for inclusion in the sample (see Materials and Methods) for each layer from each animal. The numbers in parentheses indicate the numbers of cells that had smooth or sparsely spined

$\begin{aligned} & \text { Table 1. Numbers of cells sampled in each cortical layer from } \\
& \text { each animal }\end{aligned}$
\begin{tabular}{lllllll} 
Age & Layer 2-4B & Layer 4C & Layer 5 & Layer 6 & Subplate & Total \\
\hline E100 & 1 & 0 & 7 & $24(3)$ & $2(1)$ & $34(4)$ \\
E108 & 4 & 2 & 2 & 16 & 0 & 24 \\
E122 & 14 & $9(3)$ & $13(2)$ & $26(3)$ & 0 & $62(8)$ \\
E135 & $14(1)$ & 7 & $14(3)$ & $19(2)$ & 0 & $54(6)$ \\
E145 & $16(1)$ & $3(1)$ & $5(3)$ & $16(1)$ & 0 & $40(6)$ \\
Total & $49(2)$ & $21(4)$ & $41(8)$ & $101(9)$ & $2(1)$ & $214(24)$ \\
\hline
\end{tabular}

Values in the Age column indicate the estimated gestational age of each animal in days postconception. All other values indicate the numbers of cells sampled. Numbers outside parentheses indicate spiny, presumed excitatory neurons. Numbers in parentheses indicate smooth or sparsely spined, presumed inhibitory neurons. 
dendrites and are presumed inhibitory. These constitute 24 of 238 $(\sim 10 \%)$ of the total sample. Our analyses here focus exclusively on the remaining 214 spiny neurons. Our sample is dominated by neurons in the deep layers. This is because the diversity of cell types in deep layers, particularly layer 6 (Wiser and Callaway, 1996), suggested that it might be important to label more of them. We therefore aimed for these layers most frequently with our recording electrodes. The small numbers of cells in layer $4 \mathrm{C}$ relative to more superficial layers reflect greater difficulty of obtaining whole-cell recordings.

\section{Layer 2-4B spiny neurons}

In mature macaque monkeys, pyramidal and spiny stellate neurons in layers $2-4 \mathrm{~B}$ have a main descending axon that branches to form an extensive axonal arbor within layers $2-4 \mathrm{~B}$ and a more limited arbor in layer 5. Some cells also have limited arbors in layer 6 , but axonal branches in layer 4C are absent or extremely rare (Anderson et al., 1993; Callaway and Wiser, 1996). We find that this laminar organization develops precisely from the outset.

A total of 49 pyramidal and spiny stellate neurons in layers 2-4B were labeled and analyzed. The least mature of these cells had a main descending axon that extended downward through the deeper cortical layers without forming any collateral branches in the cortical plate (see Fig. 1a,b). This morphology was observed for the single E100 cell and for 2 of 4 E108 cells. Two of the three cells lacking axonal branches in the cortical plate, however, did have axonal branches in the subplate (Fig. 1a); the third was ambiguous in this respect because the descending axon left the plane of the brain slice in layer 5 (Fig. $1 b$ ).

More mature cells had axonal branches in the cortical plate, but they were never observed in layer 4C. Of the 2 E100-E108 cells with branches in the cortical plate, one had very short collateral branches in layer 2/3 (not shown) and the other had two branches in layer 5 (Fig. 1c); these did not have axonal branches in the subplate.

At E122, axon collateral branches in cortical layers 2-4B and 5 became more common and more extensive, but they remained absent from layer $4 \mathrm{C}$ and were rare in deep layers (Fig. 1d-f). Only 2 of 14 cells lacked axonal branches in the cortical plate, and the remaining 12 all had branches in layers $2-4 \mathrm{~B}$. However, only 3 of 14 cells had branches in layer 5 (none in layer 6). The lack of branches in deep layers did not result from truncation of the descending axon during slice preparation because all but 1 could be followed into the subplate. These observations suggest that branches from these cells are formed in the superficial layers before the deep layers. Branches in the subplate were most common at E122 and were present in 10 of 13 cells (Fig. $1 d-f ; 1$ was ambiguous because of truncation of the descending axon in layer 6).

At E135, all 14 layer 2-4B spiny neurons had axonal branches in layers $2-4 \mathrm{~B}$ and most had branches in layer 5 (9/14 cells). Secondary collateral branches were common in layers 2-4B (Fig. $2 a-c$ ) and could extend several hundred micrometers laterally within the layer (Fig. 2c). Axonal branches remained absent from layers $4 \mathrm{C}$ and 6 but were still found in the subplate. The percentage of cells with subplate branches had decreased somewhat, from $77 \%(10 / 13,1$ ambiguous $)$ at E122 to $45 \%$ at E135 (5/11, 3 ambiguous).

Layer 2-4B neurons at E145 were similar in most respects to those observed at E135 (Fig. 2d). There was, however, an increase in the percentage of cells with layer 5 branches to $93 \%(14 / 15$ cells, 1 ambiguous; comparable to mature values; Callaway and
Wiser, 1996) and a continued decrease in the percentage with axonal branches in the subplate (21\%, 3/14, 2 ambiguous). Again, all cells had axonal branches in layers $2-4 \mathrm{~B}(16 / 16)$, and no axonal branches were observed in layers $4 \mathrm{C}$ or 6 .

The layer 2-4B spiny neurons at all five prenatal ages varied from mature neurons in that they invariably projected an axon to the white matter (41/41 cells, 8 ambiguous because of truncation of the descending axon). Ten of these forty-one neurons had their somata in layer $4 \mathrm{~B}$, and the remainder were in layers $2-4 \mathrm{~A}$. In a smaller sample of postnatal neurons, only about half of the layer 2-4A neurons projected to the white matter, whereas $90 \%$ of layer 4B neurons projected to the white matter (Callaway and Wiser, 1996).

\section{Layer 4C spiny neurons}

In mature animals, the spiny neurons in layer $4 \mathrm{C}$ all have a spiny stellate dendritic morphology and their axons arborize predominantly within layer 4C and/or in more superficial layers (2-4B) (Valverde, 1985; Lund, 1988; Katz et al., 1989; Anderson et al., 1993; Callaway and Wiser, 1996). Many of these cells also have weaker axonal arbors in layers 5 and/or 6, but some lack any projection to these deeper layers. These cells do not project axons into the white matter. Although the axonal arbors of spiny stellate neurons in layers $4 \mathrm{C} \alpha$ and $4 \mathrm{C} \beta$ are similar in these respects, they differ in the sublaminar specificity of their projections to superficial layers. Layer $4 \mathrm{C} \alpha$ neurons often have axonal arbors in layer $4 \mathrm{~B}$, whereas $4 \mathrm{C} \beta$ neurons lack axonal branches in this layer (see below). The development of layer $4 \mathrm{C} \beta$ neurons, therefore, will be described separately from layer $4 \mathrm{C} \alpha$ spiny stellates.

\section{Layer $4 C \alpha$}

No layer $4 \mathrm{C} \alpha$ neurons were labeled in slices from the E100 or E108 animals, presumably because they have small cell bodies, making whole-cell recordings more difficult. A total of 12 layer 4C $\alpha$ spiny stellates were labeled in the 3 older animals. The maturity of the axonal arbors of E122 neurons appeared similar to those at E135 or E145, but in view of the variability in axonal projection patterns in mature cells, the small numbers of cells labeled at E135 $(n=2)$ and E145 $(n=2)$ preclude any meaningful consideration of possible differences. All 12 neurons are therefore considered together.

Most of the prenatal layer $4 \mathrm{C} \alpha$ spiny stellates in the sample had already projected axons to layers $3 \mathrm{~B}, 4 \mathrm{~A}$, or $4 \mathrm{~B}$ (Fig. $3 a-c$; 9/12 cells, 7/8 at E122). All 12 cells also had axonal branches within their home layer (layer $4 \mathrm{C} \alpha$ ), and 2 of these also had branches in layer $4 \mathrm{C} \beta$. Seven of eleven cells had axonal branches in layers 5 and/or 6 (Fig. $3 c ; 1$ ambiguous because of truncation of the descending axon in layer 5). Branches were slightly more common in layer 6 ( 6 cells) than layer 5 ( 4 cells). These axonal projection patterns are all consistent with those observed in mature animals, although the overall density of projections appeared to be lower.

The prenatal cells did vary from more mature cells in two important respects. Their main descending axons often extended into the white matter (Fig. $3 a-c$ ), and they sometimes gave off collaterals in the subplate (Fig. $3 a, c$ ). Of the 12 cells sampled, 7 clearly projected an axon to the white matter whereas only 1 clearly lacked a projection. The remaining 4 neurons were ambiguous in this respect because of truncation of the descending axon in the subplate ( 3 cells) or layer 5 ( 1 cell). Axonal branching in the subplate was observed for 3 of 8 cells ( 4 ambiguous). 
Figure 1. Camera lucida reconstructions of axonal and dendritic arbors of pyramidal neurons with somata in layers 2-4B. Cells were intracellularly labeled with biocytin in living brain slices from animals aged E100 $(a)$, E108 $(b, c)$, or E122 $(d-f)$. The least mature neurons $(a$, $b$ ) have a main descending axon originating at the base of the cell body and extending through the cortical plate without branching. The cell in $a$ does have an axonal branch in the subplate. More mature neurons also have 100 - to $200-\mu \mathrm{m}$-long axonal branches in layers $2-4 B$ $(d-f)$ or layer $5(c)$, but cells with branches in layer 5 are relatively uncommon at these ages (see Results). Most E122 neurons also have axonal branches in the subplate. All of these cells have a pyramidal dendritic morphology with a prominent apical dendrite emerging from the top of the cell body. Laminar boundaries are indicated by straight horizontal lines, and the numbers to the left of each figure identify the layers. When the layers are not identified, they are the same as for the cell located to the left. The thick horizontal lines are scale bars. SP, Subplate. Scale bars, $100 \mu \mathrm{m}$.

\section{Layer $4 C \beta$}

The local axonal arbors of mature layer $4 \mathrm{C} \beta$ spiny stellate neurons project most densely to layers $4 \mathrm{~A}$ and $3 \mathrm{~B}$. These superficially projecting axons pass through layer $4 \mathrm{~B}$, on their way to more superficial layers, without branching. In previous studies, reconstructions of more than 30 intracellularly labeled layer $4 \mathrm{C} \beta$ spiny stellates from postnatal animals have never revealed an axonal branch in layer 4B (Katz et al., 1989; Anderson et al., 1993; Callaway and Wiser, 1996) (H. Yabuta and E. M. Callaway, unpublished observations). Furthermore, I have closely inspected axons anterogradely labeled by extracellular biocytin injections in layer $4 \mathrm{C} \beta$ of brain slices from postnatal animals, following more than 100 collaterals through layer $4 \mathrm{~B}$ without detecting a branch.

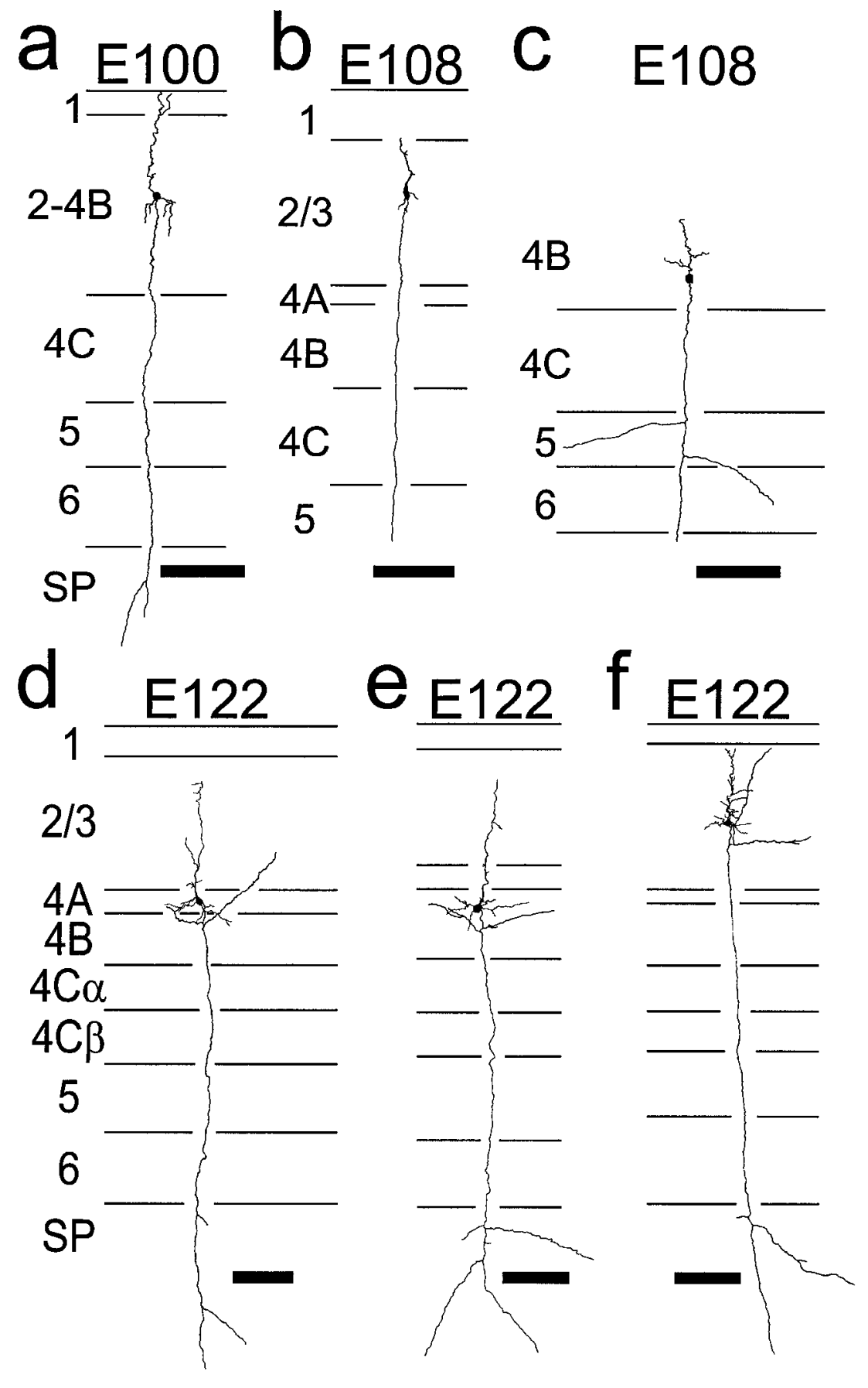

In contrast to these findings in postnatal animals, we have detected layer $4 \mathrm{~B}$ axonal branches from prenatal layer $4 \mathrm{C} \beta$ spiny neurons (Fig. 4). In the youngest animal (E100), layer 4C neurons were not sampled. However, a small number of layer $4 \mathrm{C} \beta$ spiny neurons $(n=9)$ were labeled in older animals: 2 at E108, 1 at E122, 5 at E135, and 1 at E145. Nissl stain clearly distinguished layer $4 \mathrm{C} \beta$ from $4 \mathrm{C} \alpha$, and layer $4 \mathrm{~B}$ from $4 \mathrm{C} \alpha$ and $4 \mathrm{~A}$ in sections from the slices containing the E122 and older cells, but did not distinguish layer $4 \mathrm{C} \alpha$ from $4 \mathrm{C} \beta$ at E108. Nevertheless, the 2 E108 cells were well within the lower half of layer $4 \mathrm{C}$ and, therefore, presumably within layer $4 \mathrm{C} \beta$ (Fig. $4 a, b$ ).

Three of the nine layer $4 \mathrm{C} \beta$ spiny neurons clearly had axonal branches in layer $4 \mathrm{~B}$ (Fig. $4 b, c, e$ ). One of these cells was from an 


\section{a}

E135

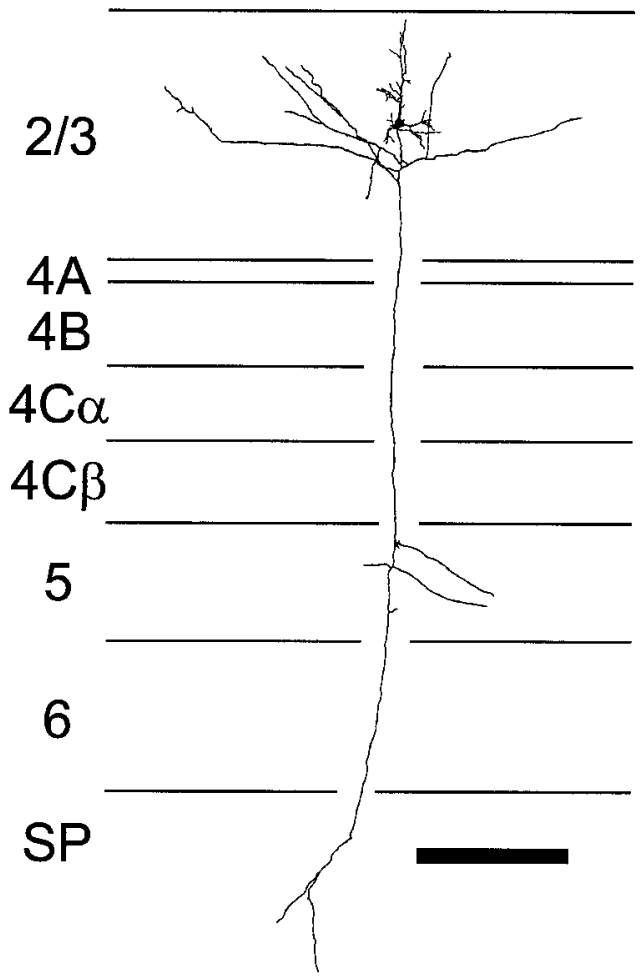

b

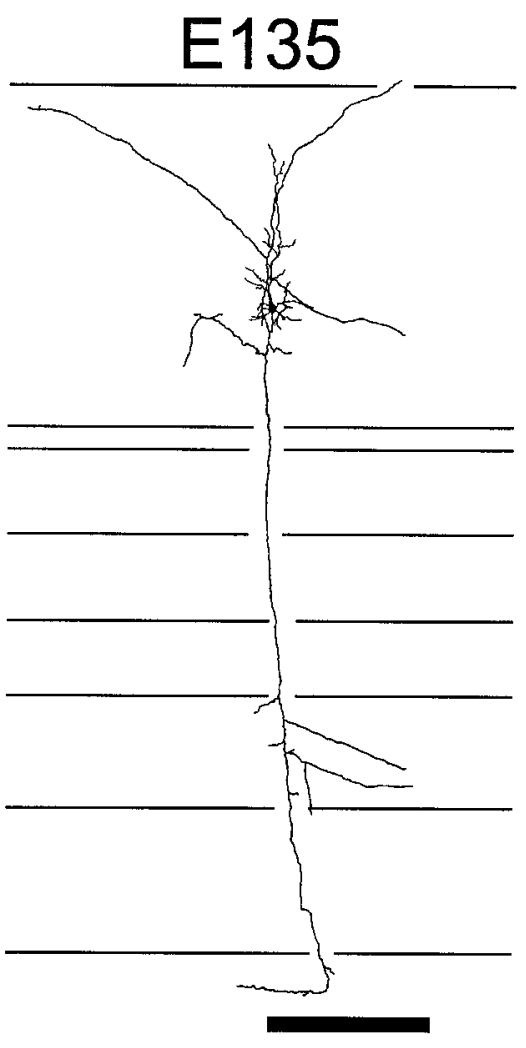

\section{E135}
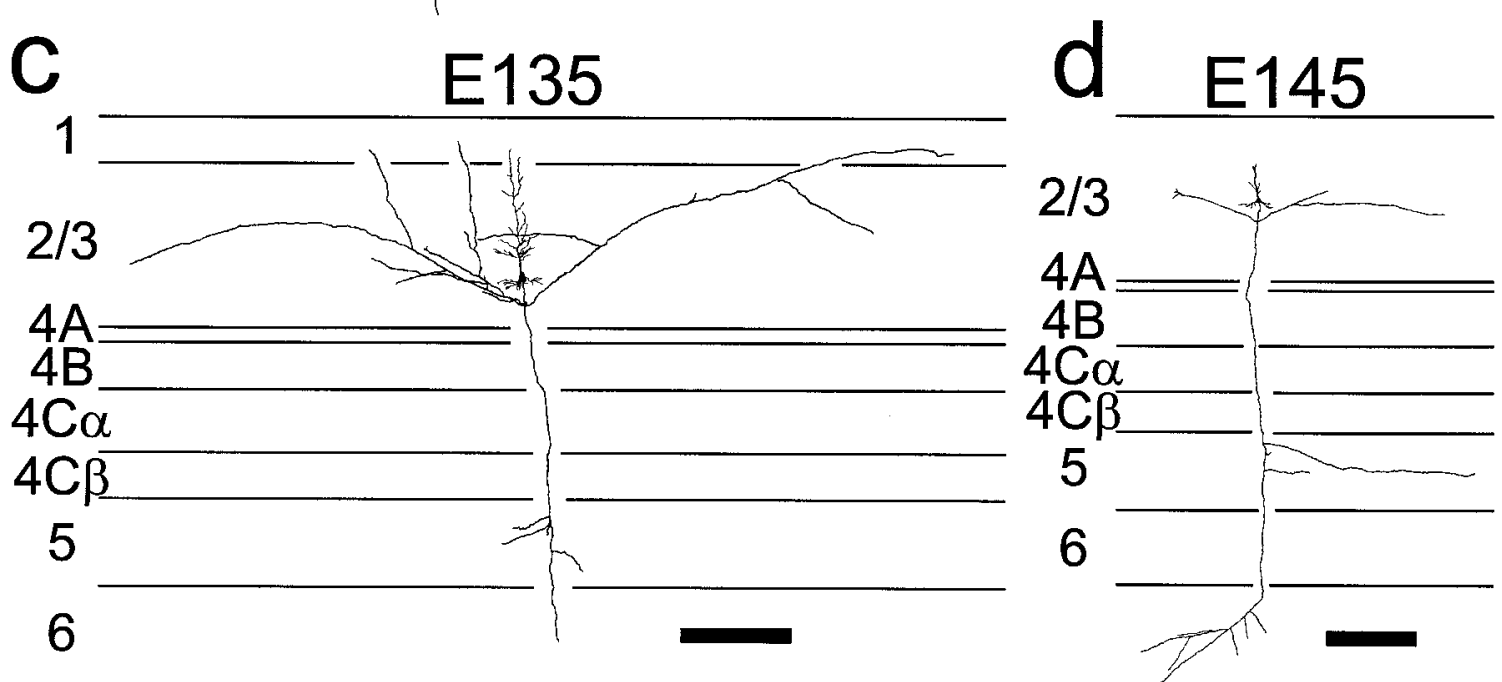

Figure 2. Camera lucida reconstructions of layer 2/3 pyramidal neurons intracellularly labeled in E135 $(a-c)$ or E145 $(d)$ slices. These cells all have a main descending axon extending through the cortical plate and into the subplate. Each cell has axonal branches in layers $2 / 3$ and 5 that extend laterally for several hundred microns. Many of the laterally projecting axon collaterals also give off secondary branches. There are no axonal branches in layer $4 C$. Many cells at these ages have axonal branches in the subplate $(a, b, d)$. Conventions are as in Figure 1 . Scale bars, $200 \mu \mathrm{m}$.

E108 slice, and it had two short axonal branches in layer 4B (Fig. $4 b)$. A second cell was the lone $4 \mathrm{C} \beta$ spiny stellate labeled at E122; it had a single axonal branch in layer $4 \mathrm{~B}$, and both collaterals ascended vertically to layer $2 / 3$ without further branching (Fig. $4 c)$. The third was labeled in a slice from the E135 animal, and it had four axonal branches in layer 4B (Fig. 4e).

Four other cells from E135 slices lacked layer 4B axonal branches, as did the lone cell labeled from the E145 animal and 1 of the E108 cells (e.g., Fig. 4a,d,f). Although I am reluctant to make strong conclusions based on layer $4 \mathrm{~B}$ branches observed for just 3 cells, the relative incidence of such branches prenatally $(33 \%, 3 / 9$ cells) is significantly greater than even a conservative estimate from postnatal intracellular labeling results $(0 / 30$ cells, $p<0.01$, Fisher exact test), and when considered in the context of 

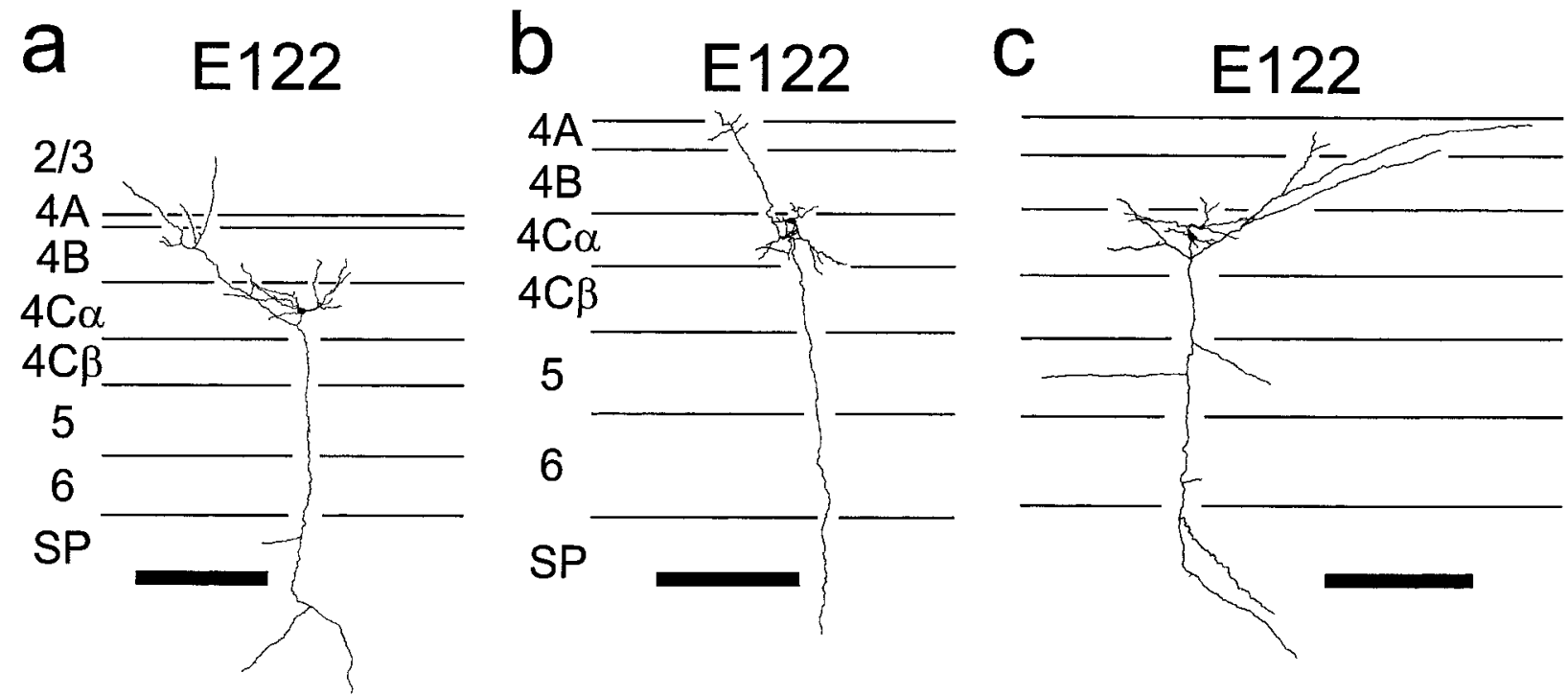

Figure 3. Layer $4 \mathrm{C} \alpha$ spiny stellate neurons labeled in E122 slices. All three cells $(a-c)$ have a main descending axon extending into the subplate and either one $(a, b)$ or two $(c)$ axonal branches originating in layer $4 C \alpha$ and extending to and branching further in more superficial layers. Cells $a$ and $c$ have axonal branches in the subplate, and cell $c$ also has branches in layers 5 and 6 . Conventions are as in Figure 1 . Scale bars, $200 \mu \mathrm{m}$.

the hundreds of axons observed from extracellular layer $4 \mathrm{C} \beta$ injections, the result is still more compelling. These observations, therefore, suggest that at least some layer $4 \mathrm{C} \beta$ spiny neurons form transient axonal branches in layer 4B (see Fig. 14 for a summary schematic of possible developmental sequence).

The youngest layer $4 \mathrm{C} \beta$ spiny neurons also appeared to have transient apical dendrites, as reported previously for spiny stellate neurons in rat somatosensory cortex (Peinado and Katz, 1990) and perhaps also cat striate cortex (Callaway and Katz, 1992). Both E108 cells had an apical dendrite extending into layer 2 with short $(<20 \mu \mathrm{m})$ branches in layers $2 / 3$ and $4 \mathrm{~B}$ (Fig. $4 a, b)$. Most of the dendritic branches were, however, within lower layer $4 \mathrm{C}$. Layer $4 \mathrm{C} \beta$ cells labeled in slices from older animals all lacked dendrites extending outside layer $4 \mathrm{C}$.

Although layer $4 \mathrm{C} \beta$ spiny neurons, like those in $4 \mathrm{C} \alpha$, occasionally had axonal branches in layer $4 \mathrm{~B}$, the two populations did differ clearly in several respects. First, the layer $4 \mathrm{C} \alpha$ neurons were somewhat more likely to have branches in layer $4 \mathrm{~B}(50 \%, 6 / 12$ cells vs $33 \%, 3 / 9$ cells), but this difference is not statistically significant ( $p>0.25$, Fisher exact test). More striking, however, were the lack of projections to the white matter and the lack of axonal branching in the subplate and infragranular layers (layers 5 and 6 ) for layer $4 C \beta$ spiny neurons ( $0 / 9$ cells). Two-thirds of the layer $4 \mathrm{C} \beta$ spiny neurons did not have any axons descending below layer 4C (6/9 cells), whereas one-third (3/9) had a descending axon extending unbranched into layer 5 or 6 . This contrasts with $88 \%$ of prenatal layer $4 \mathrm{C} \alpha$ spiny stellates that had an axonal projection to the white matter (7/8 cells), 38\% with axonal branches in the subplate $(3 / 8$ cells $)$, and $64 \%$ with infragranular branches (7/11 cells; see details above).

\section{Layer 5 pyramidal neurons}

In postnatal macaque monkeys, layer 5 pyramids in V1 can be classified into three groups (cf. Callaway and Wiser, 1996). Approximately $80 \%$ of layer 5 pyramids (termed "class A") do not project axons below layer 5 (their axonal arbors are entirely intrinsic to V1). Instead, they have recurrent axon collaterals in layer 5 that extend to layers $2-4 \mathrm{~B}$, where they form dense arbors.
The remaining $20 \%$ of layer 5 pyramids do project to the white matter. Most of these have a distinctive "backbranching" dendritic morphology (e.g., Fig. 7c) and long, lateral axon collaterals in layer 5 and occasionally layer 6 (termed "class B"). The most rare layer 5 pyramids have a very large soma and a "tall" apical dendritic morphology (Lund and Boothe, 1975; Valverde, 1985) and probably project to the superior colliculus (Lund et al., 1975). Neither the class A nor the class B pyramids have axonal branches in layer $4 \mathrm{C}$, but the pattern of local axonal projections of tall layer 5 pyramids is unknown.

A total of 41 layer 5 pyramidal neurons were included in our sample: 7 at E100, 2 at E108, 13 at E122, 14 at E135, and 5 at E145 (see Table 1). As these cells developed, they formed axonal arbors precisely in the same cortical layers as they do in maturity. Presumptive class A cells formed extensive axonal arbors in layers 2-4B. Presumptive projection neurons formed laterally projecting arbors in deep layers, and no cells formed axonal arbors in layer $4 \mathrm{C}$.

At E100 and E108, all 9 layer 5 pyramidal neurons projected a main descending axon to the white matter (Fig. 5). Four of these cells had axon collateral branches in the subplate (Fig. $5 d$ ), and 6 had branches in layer 6 (Fig. $5 c, d ; 2$ of these projected to both the subplate and layer 6). Four of nine had a single recurrent axon collateral that originated from the main descending axon, just below the cell body (usually in layer 5) and then ascended to more superficial layers (Fig. $5 a, b$ ). Of the 4 cells with an ascending collateral, 1 stopped in layer $4 \mathrm{C}$ without branching, 1 extended unbranched to layer 1 , and 2 extended into layers $2-4 \mathrm{~B}$ where they formed a short branch. One of these branches turned into layer $4 \mathrm{C}$ where it ended. Cells lacking recurrent collaterals typically had short branches in layers 5 and or 6 (Fig. $5 c, d$ ), but for 1 cell a layer 5 branch extended far laterally into layer 6 (Fig. $7 a$ ). This cell's apical dendrite extended to layer 1, suggesting that it might be a presumptive "tall" pyramid (see below).

By E122, all of the layer 5 pyramids had taken on characteristics of either the projecting (class B or tall; Fig. 7) or the nonprojecting (class A; Fig. 6) layer 5 pyramids. Of all 32 neurons 

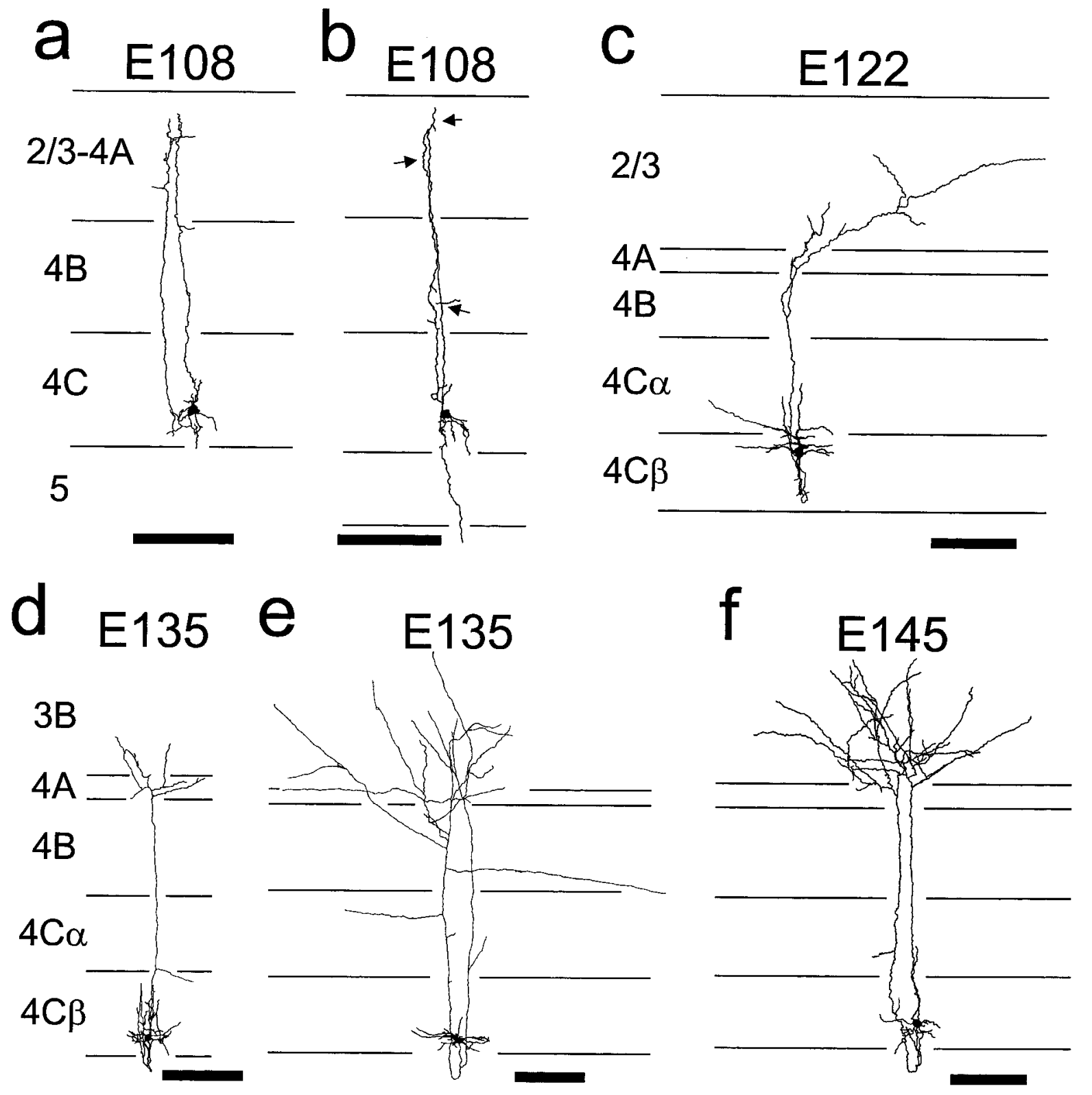

Figure 4. Layer 4C $\beta$ spiny neurons from animals aged E108 $(a, b), \mathrm{E} 122(c), \mathrm{E} 135(d, e)$, and E145 ( $f)$. Two of the cells have a spiny stellate dendritic morphology, typical of mature layer $4 C$ spiny neurons $(d, e)$. The remaining four cells all have a long apical dendrite. The apical dendrites are most prominent for the E108 cells $(a, b)$. These dendrites extend into layer 2 and have very short branches in layers $2 / 3$ and $4 B$. For cell $a$, the apical dendrite is to the right of a recurrent axon collateral in superficial layers, but for the cell in $b$, the apical dendrite and an axon cross over one another several times; for this cell, arrows point to the axon. For cells $c$ and $f$, the apical dendrite extends only into layer $4 C \alpha$. All of these cells have one $(a-d)$ or two $(e, f)$ recurrent ascending axon collaterals extending into layer $2 / 3$. Three of these cells have axonal branches in layer $4 B$ (b, $c$, $e$; the lowest arrow in $b$ points to a layer $4 B$ axonal branch), whereas the remaining cells only have branches in more superficial layers, and sometimes layer $4 C$. Cell $b$ also has a descending axon extending into layer 6. Conventions are as in Figure 1. Scale bars, $100 \mu \mathrm{m}$.

from E122, E135, and E145 animals, only 1 formed axonal branches in the subplate and only 6 projected to the white matter (none was ambiguous). The proportion of neurons projecting to the white matter had decreased, therefore, from $100 \%(9 / 9)$ at E100-E108 to $19 \%(6 / 32)$ at E122-E145, similar to postnatal values (see above). All 26 of the nonprojecting neurons had the local pattern of axonal arborization typical of layer 5 , class A pyramids (Fig. 6). Two of the six projecting neurons also had this pattern of local axonal arborization and, therefore, are referred to as presumptive class A neurons (1 cell at E135 and 1 at E145; Fig. $6 d$; see below). The remaining 4 projecting neurons had anatomical characteristics typical of either class B or tall layer 5 pyramids and are referred to as presumptive layer 5 projection neurons.

At E122, 11 of 13 layer 5 pyramids were presumptive class A cells (Fig. 6a,b). All 11 cells had a main descending axon that either curved abruptly just below the cell body and ascended to superficial layers or branched just below the cell body, giving rise to two or more recursive collaterals that ascended to superficial layers. Most of these cells (10/11) formed short axon collateral branches in layers $2-4 \mathrm{~B}$, and 1 extended its single recursive axon to layer 4A without branching. For some cells, however, the 

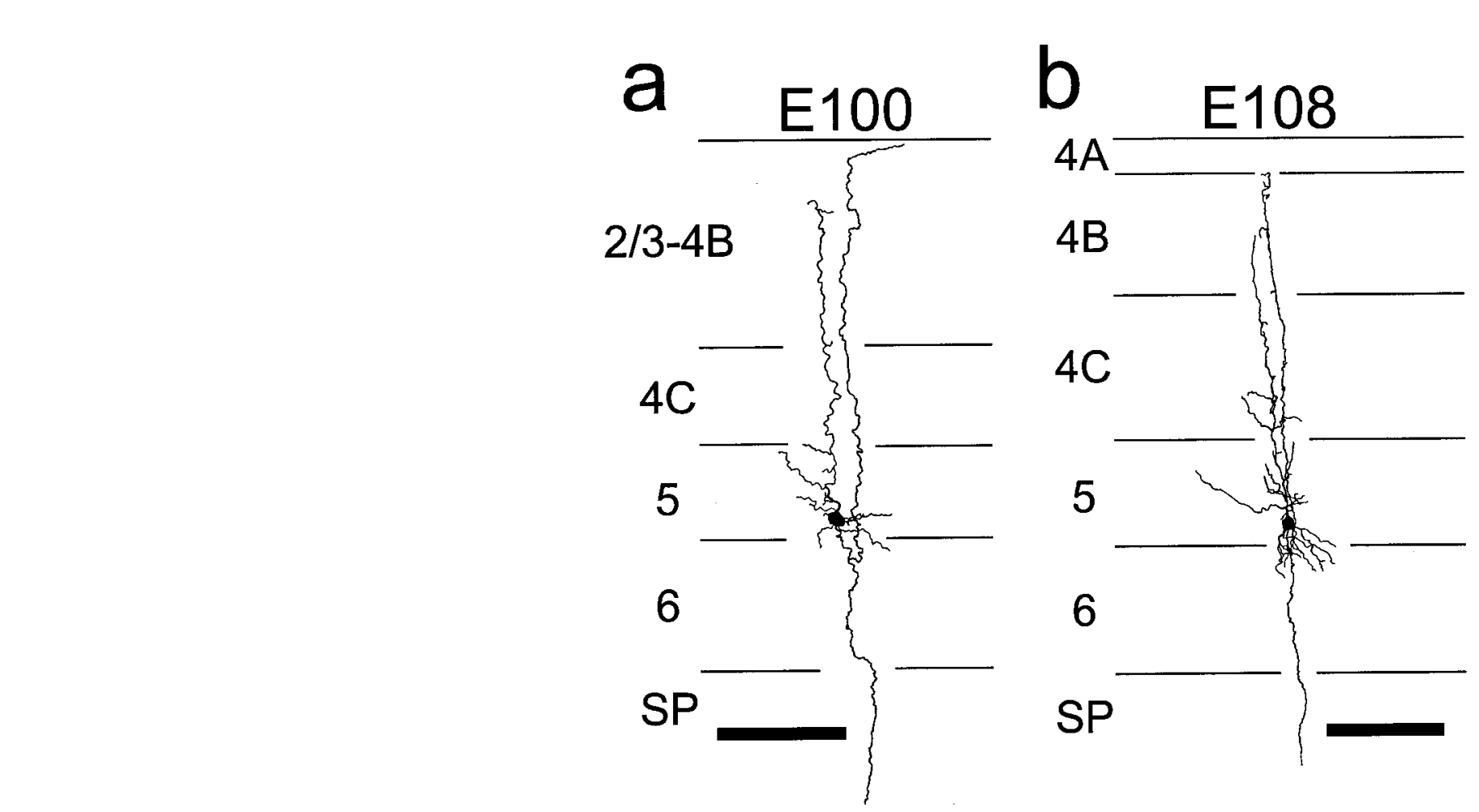

Figure 5. Layer 5 pyramidal neurons from animals aged E100 $(a, c)$ and E108 $(b, d)$. All four cells have a main descending axon extending into the subplate. The cells shown in $a$ and $b$ each have a recurrent axon collateral ascending either to the top of layer $2(a)$ or just to layer $4 B(b)$. For both of these cells, the ascending axon is to the right of the apical dendrite. The cells shown in $c$ and $d$ have axonal branches in layer 6 , but none of the collaterals extends above layer 5 . All four cells have a prominent apical dendrite extending either into layer $2(a, c, d)$ or just to layer $4 B(b)$. Cell $d$ 's apical dendrite bifurcates in layer $4 C$, and each branch extends up to layer 2 . This cell also has an axonal branch in the subplate. Conven-
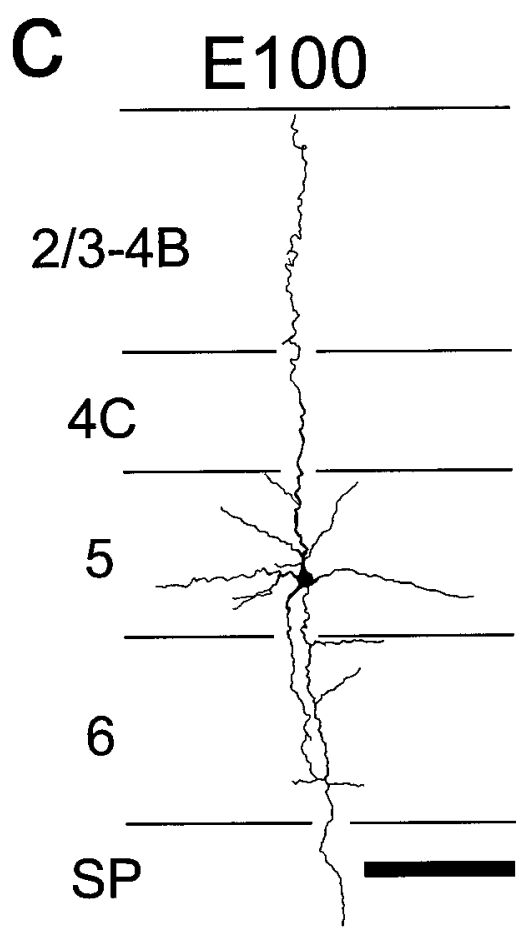
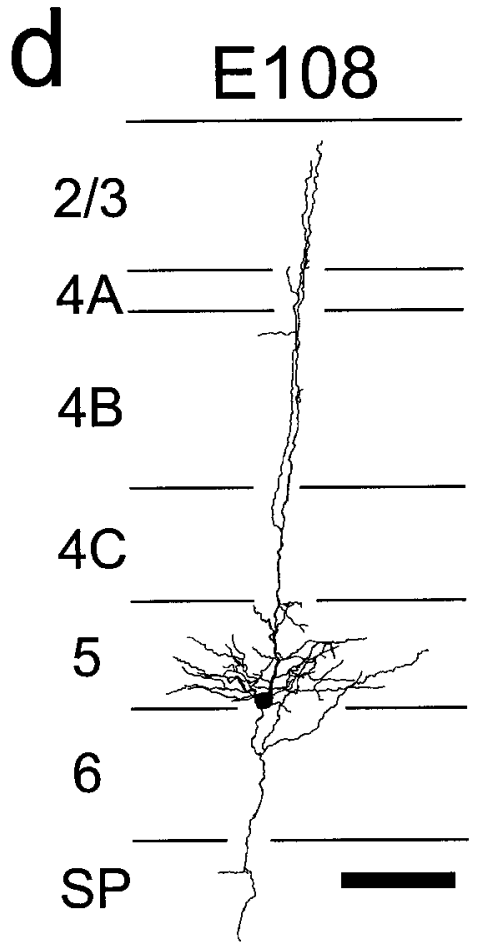
tions are as in Figure 1. Scale bars, $100 \mu \mathrm{m}$.

lateral axons in layers 2-4B extended up to several hundred micrometers (Fig. 6b). No axonal branches were present in layer $4 \mathrm{C}$ for any cell. One of the cells had short lateral branches in layer 5 (Fig. 6b; also typical of some mature class A cells).

Axonal arbors of presumptive class A cells became more dense in layers $2-4 \mathrm{~B}$ at subsequent ages, but they maintained a precise laminar organization. Twelve of thirteen E135 neurons were presumptive class A cells (Fig. $6 c, d$ ). One of these varied from class A cells observed in previous studies of postnatal neurons in that it did project its descending axon to the white matter (Fig. $6 d$ ). This same neuron also was the only cell with an axonal branch in layer 4C. However, this branch descended obliquely back into layer 5 where it branched again, giving rise to two collaterals that rose vertically into layer $2 / 3$. The layer $2-4 \mathrm{~B}$ axonal arbors of presumptive class $A$ cells were generally more extensive and more dense than at E122, but there was considerable overlap between the populations. Much of the increase in density of projections to superficial layers appeared to be caused 


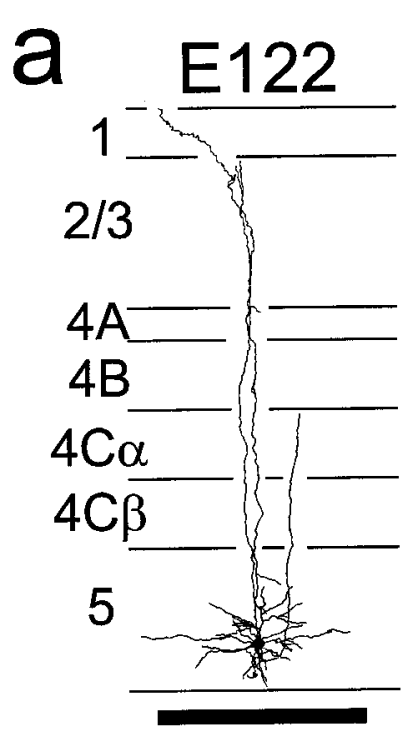

C E135

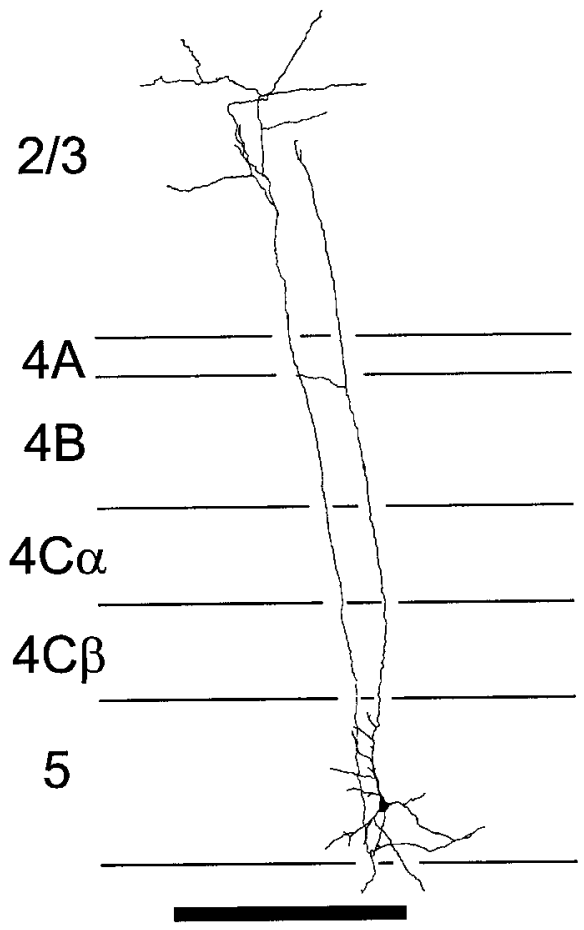

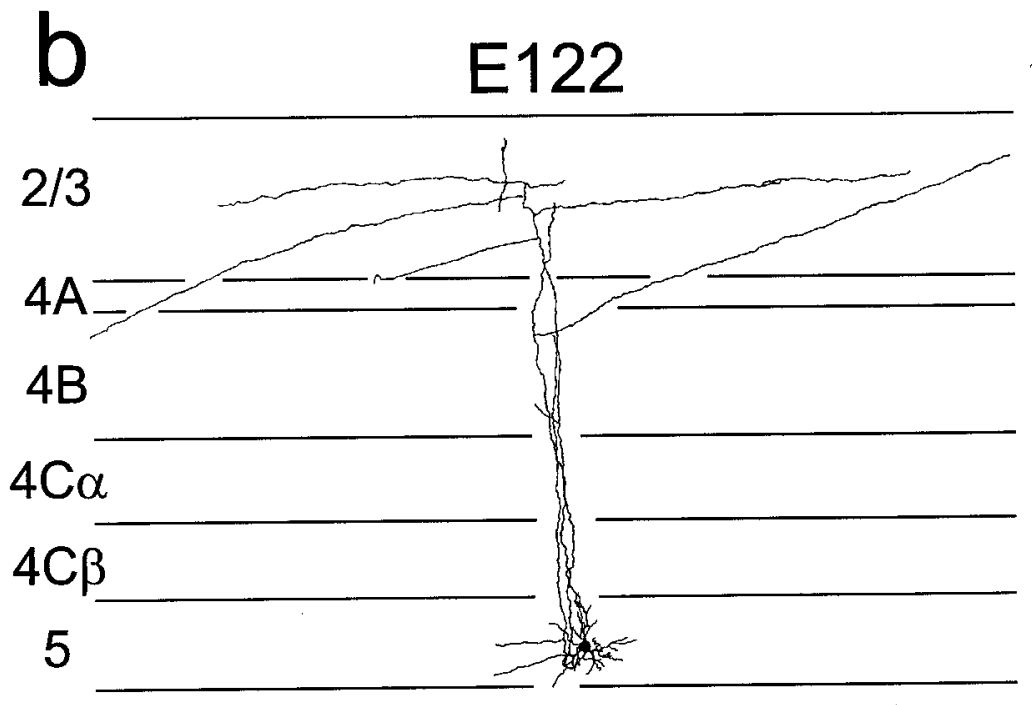

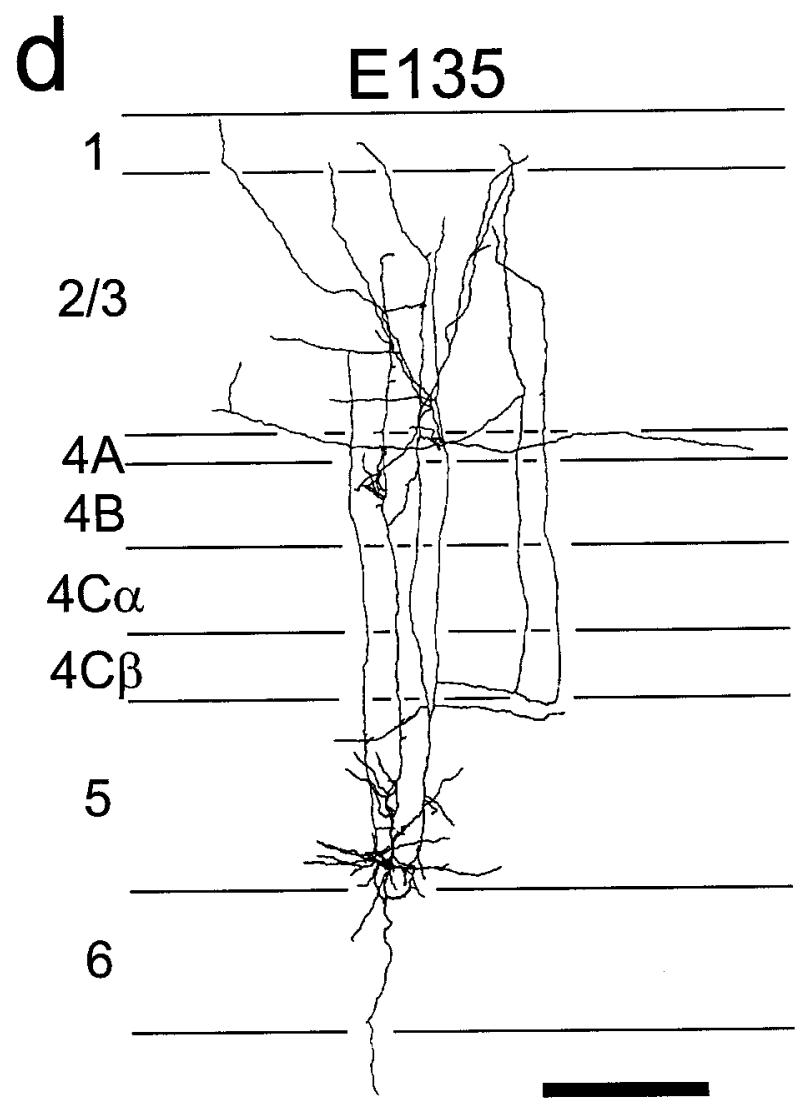

Figure 6. Presumptive class A layer 5 pyramidal neurons aged E122 $(a, b)$ or E135 $(c, d)$. All four neurons have recurrent ascending axon collaterals extending into layer 2 or layer 1 and forming laterally projecting branches in layers $2-4 B$ and 5 . The least mature cell $(a$, E122) has only very short axonal branches in layer 2/3, whereas the remaining three cells have longer branches. Cells $a-c$ all lack a descending axon, but the main descending axon of cell $d$ extends into the white matter. Each cell has an apical dendrite extending into layer $4 B$ or higher. The apical dendrite of cell $a$ extends to the layer $1 /$ layer 2 border and has a short branch at the top of layer $4 A$. Cell $b$ 's apical dendrite only extends to the top of layer $4 B$ and branches once at the bottom of layer $4 B$. Cell $c$ 's apical dendrite extends into layer $2 / 3$ and has a short branch in layer $2 / 3$ and another at the top of layer $4 B$. The apical dendrite of cell $d$ extends into and forms short branches in layer $2 / 3$ and also has several oblique branches in layer $4 B$ (all of the layer $4 B$ branches from this cell are dendrites). Conventions are as in Figure 1. Scale bars, $200 \mu \mathrm{m}$. 
by an increase in the number of ascending collaterals rising from layer 5. At E122, 6 of 11 cells had just a single ascending collateral and the other 5 cells formed a recursive branch in layer 5 that provided an additional ascending collateral. However, at E135 11 of 13 presumptive class A cells had multiple ascending collaterals.

Four of five layer 5 pyramids from the E145 animal were presumptive class A cells. One of these projected to the white matter. The local axonal arbors of these cells were indistinguishable from the E135 cells.

Four of the thirty-two layer 5 pyramids labeled at E122-E145 were presumptive projection neurons (Fig. $7 b, c$ ). Two of these were labeled in slices from the E122 animal. The local axonal arbors of these cells were different from those of presumptive class A cells in that both had axonal branches in layer 6. One of these, however, was not distinguished in any other respect. Its single layer 6 axonal branch ascended to layer 5 where it ended. In view of the large proportion of E100-E108 cells with axonal branches in layer 6 and projections to the white matter (6/9), this cell conceivably might have been destined to develop the characteristics of a class A neuron rather than a projection neuron.

The morphology of the other E122 projection neuron was unique (Fig. 7b). Its apical dendrite extended to and branched in layer 1, whereas the apical dendrites of all of the presumptive class A cells ended below layer 1. The apical dendrite also had numerous fine lateral processes throughout the cortical depth, and the network of basal dendrites was unusually dense, whereas presumptive class A apical dendrites had few or no branches above layer 5. This cell also had axon collaterals extending laterally for more than $200 \mu \mathrm{m}$ within layers 5 and 6 . This pattern of dendritic arborization is reminiscent of the "giant" or "tall" layer 5 pyramids observed in Golgi preparations (Lund and Boothe, 1975; Valverde, 1985). Their mature pattern of axonal arborization in macaque V1 is unknown, but in other species tall pyramids have local axonal arbors in deep layers (cf. ChagnacAmitai et al., 1990). The lone E135 presumptive projection neuron and the E100 neuron with long, lateral axons in layers 5 and 6 (Fig. 7a; see above) both had similar axonal and dendritic morphologies, suggesting that they, too, might have been destined to be "tall" pyramids in maturity.

The last presumptive projection neuron was observed in an E145 slice. Its dendritic morphology was similar to that of "backbranching," class B projection neurons observed postnatally (Fig. $7 c$ ). Its local axonal arbor was also similar to that of backbranching cells in that it had laterally projecting axonal branches in layers 5 and 6 . However, it differed from mature cells in having an extensive axonal arbor in the subplate.

\section{Layer 6 pyramidal neurons}

Mature anatomical features

Postnatal layer 6 pyramidal neurons fall into two major classes (Wiser and Callaway, 1996). Class II neurons have axonal arbors that generally avoid layer $4 \mathrm{C}$ and have extensive dendritic branches in layer 5. There are at least two types of class II neurons. The most distinctive of the class II neurons is type IIB (e.g., Fig. 9c). In postnatal animals, these cells have been found only deep in layer 6 . They lack a projection to the white matter and, instead, have widespread intrinsic axonal arbors in layers 5 and $2-4 \mathrm{~B}$ but not in layer $4 \mathrm{C}$. In these respects, they are reminiscent of layer 5, class A pyramids (see above). The dendritic arbors of type IIB neurons are also distinctive; the apical dendrite branches extensively in layer 5 and never extends above layer 5 . The remaining class II neurons are termed type IIA.
Their local axonal arbors typically extend for long distances laterally within layers 5 and 6 , and $\sim 30 \%$ project an axon to the white matter. In these respects, the type IIA neurons are reminiscent of layer 5 projection neurons. However, some type IIA neurons do have axonal arbors in more superficial layers.

Class I neurons, on the other hand, are characterized by dense axonal arbors in layer 4C and a lack of dendritic branches in lower layer 5. They also lack axonal branches in layer 5. There are five clearly distinguishable types of class I neurons, defined principally by differences in the laminar and sublaminar specificity of their axonal arbors. Each also has a distinct distribution within the depth of layer 6 (see Fig. 15 for schematic illustrations of mature class I cell types).

Type $\mathrm{I} \alpha$ neurons have dense axonal arbors in layer $4 \mathrm{C} \alpha$, but not in $4 \mathrm{~B}$ or $4 \mathrm{C} \beta$ (Fig. 13e). Their cell bodies are found in the middle of layer 6 (at depths of 40-60\%; see Materials and Methods), but never in the upper $40 \%$. The only other type of layer 6 pyramid with axons targeting layer $4 \mathrm{C} \alpha$ is type IC (not shown). These cells have dense axons throughout layer $4 \mathrm{C}$ and in layers $4 \mathrm{~A}$ and $3 \mathrm{~B}$. They are found only in the bottom $40 \%$ of layer 6 . Thus, in mature animals, no cells in the upper $40 \%$ of layer 6 have axonal branches in layer $4 C \alpha$. Type IC neurons can also project an axon to the white matter, whereas type I $\alpha$ neurons with a white matter projection have not been detected postnatally.

Two cell types, $\mathrm{I} \beta$ and $\mathrm{I} \beta \mathrm{A}$, have axonal arbors specific for layer $4 \mathrm{C} \beta$, avoiding layer $4 \mathrm{C} \alpha$ (Fig. 11). The type I $\beta$ A cells also have axonal arbors in layers $4 \mathrm{~A}$ and $3 \mathrm{~B}$, and their somata are confined to the upper half of layer 6 , whereas the somata of type I $\beta$ neurons are found throughout the depth of layer 6 . These are the only class I cell types found in the upper $40 \%$ of layer 6 . Approximately $40 \%$ of type I $\beta$ and I $\beta$ A neurons project to the white matter.

Finally, type Im neurons are found in the middle of layer 6 (depths of $40-60 \%$ ) and have axonal arbors that specifically target the middle third of layer $4 \mathrm{C}$, with few or no branches at the edges (Fig. 12c). Like type I $\alpha$ cells, none with a projection to the white matter has been detected postnatally.

\section{Prenatal neurons can be categorized according to presumptive mature fates}

At the earliest ages in our sample (E100-E108), layer 6 pyramidal neurons were extremely immature. Despite this immaturity, several observations suggested that they could already be divided into two groups: (1) presumptive type IIA neurons that in maturity would lack projections to more superficial layers, and (2) presumptive class I and class II (mostly type IIB) neurons that in maturity would have axonal arbors in more superficial layers. These groupings are similar to the presumptive class A versus presumptive projection neuron categories described for layer 5 pyramids (see above). One group has local, recurrent axon collaterals (Fig. 8b), whereas the other has local, laterally projecting collaterals (Fig. $8 a$; see below).

By E122 most of the neurons with recurrent ascending axon collaterals had laminar patterns of axonal and dendritic arborization that, along with other anatomical features, were highly suggestive of cell types observed in postnatal animals, allowing more precise categorization of presumptive fates (i.e., type I $\alpha$ vs I $\beta$ A or IIB; Figs. 9-12). The proportion of neurons that could be categorized and the certainty of classification increased with the increasing maturity of neurons observed at later ages (E135E145). Although the classification of neurons according to presumptive fates sometimes might be uncertain or inaccurate (see 

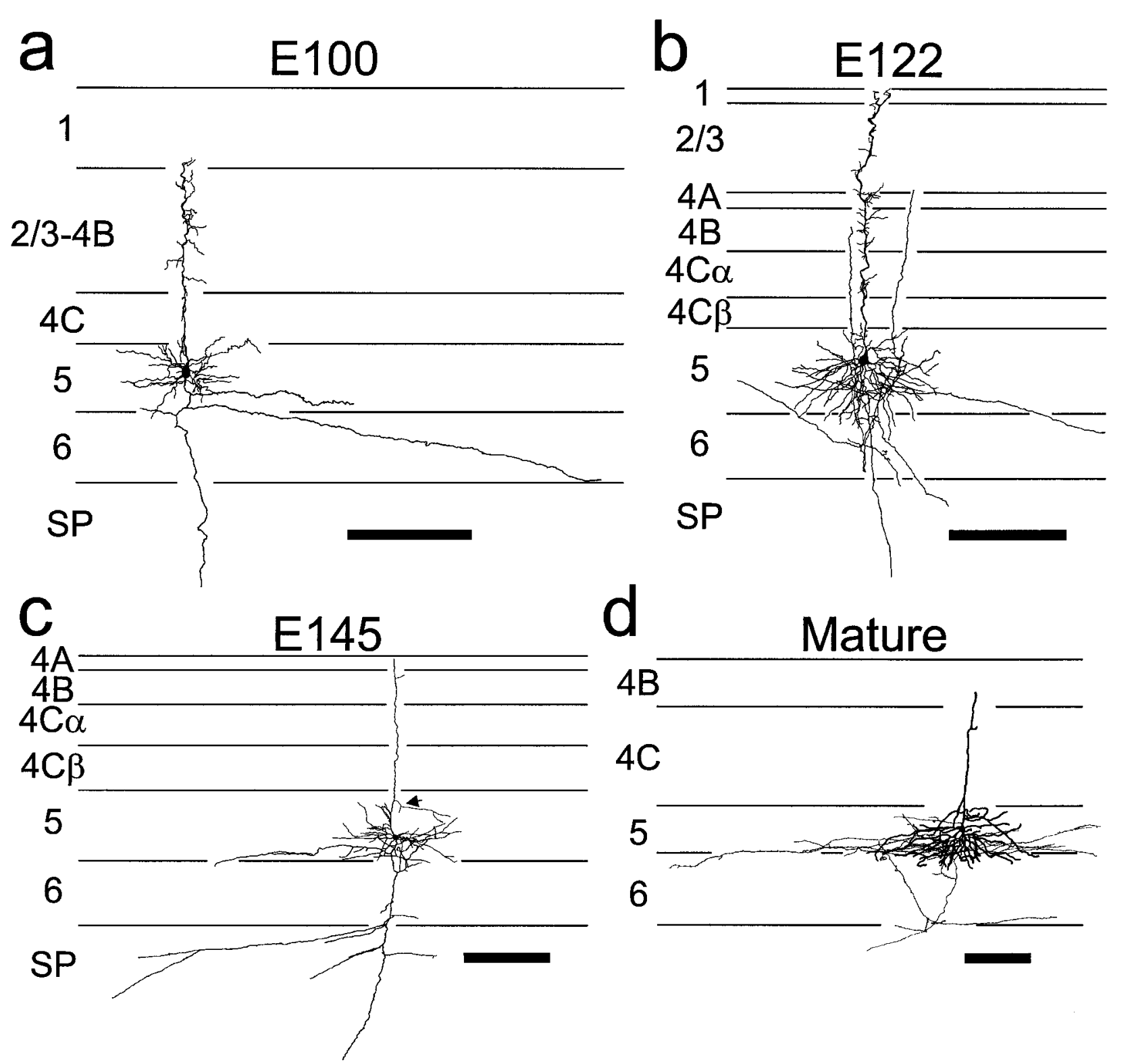

Figure 7. Mature $(d)$ and presumptive layer 5 projection neurons aged E100 $(a)$, E122 $(b)$, or E145 $(c)$. Cells $a$ and $b$ have large cell bodies and "tall" apical dendrites extending into layer 1, with numerous fine dendritic process in layers 1-5. In contrast, cell $c$ has an apical dendrite that extends only up to layer $4 A$, and it is relatively devoid of branches. It does have, however, a "backbranching" dendrite near the top of layer 5 (arrow). A mature "backbranching" layer 5 projection neuron $(d)$ has similar dendritic branches. All of these cells have a main descending axon extending into the subplate/white matter and laterally projecting axon collaterals in deep cortical layers. For cells $c$ and $d$, axons in the cortical plate are mostly at the bottom of layer 5. Cell $c$ also has a substantial axonal arbor in the subplate. Conventions are as in Figure 1. Scale bars, $200 \mu \mathrm{m}$. Panel $d$ is from Callaway and Wiser (1996).

Results and Discussion), it is helpful for organizational purposes to describe the immature neurons that we observed according to these groupings. The bases on which these classifications are made are described in detail below, including characteristics that are inconsistent as well as consistent with the groupings.

Our sample includes a total of 101 layer 6 pyramidal neurons. Of the 40 neurons sampled at E100 and E108 ( $n=24$ and $n=16$, respectively), 12 were presumptive local, laterally projecting neurons (type IIA; Fig. $8 a$ ), whereas the remaining 28 had local, recurrent ascending axon collaterals (Fig. $8 b$ ). Twenty-six neurons were sampled at E122, and 10 of these were laterally projecting, with the remaining 16 having ascending axon collaterals.
Of the 16 cells with recurrent collaterals, 4 lacked branches in more superficial layers, precluding further categorization (Fig. $8 c$ ). Of the remaining 12 neurons, 1 was a presumptive type IIB neuron, 4 were $\mathrm{I} \beta$ or $\mathrm{I} \beta \mathrm{A}, 5$ were $\mathrm{I} \alpha, 1$ was $\mathrm{Im}$, and 1 remained ambiguous despite axonal branching in superficial layers (see further details below).

All 35 of the layer 6 pyramids sampled at E135 and E145 could be assigned a presumptive cell type. Of the 19 E135 neurons, 2 were presumptive type IIA neurons, 6 were IIB, 7 were I $\beta$ or $\mathrm{I} \beta \mathrm{A}, 2$ were $\mathrm{I} \alpha$, and 2 were Im. Of the 16 E145 neurons, 5 were presumptive type IIA neurons, 2 were IIB, 5 were I $\beta$ or I $\beta$ A, and 4 were $\mathrm{I} \alpha$. 
Figure 8. Layer 6 pyramidal neurons intracellularly labeled in slices from animals aged $\operatorname{E} 108(a, b)$ or E122 $(c)$. All three cells extend their main descending axon into the subplate, but cell $a$ has several axonal branches in the subplate and lacks a recurrent ascending collateral, whereas cells $b$ and $c$ each have a single recurrent ascending axon extending either to layer $4 A$ (b, arrows) or to the top of layer $4 C$ (c, left of apical dendrite). The apical dendrites of cells $a-c$ extend into layers $4 C$, 1 , and $4 B$, respectively. Cell $a$ has only extremely short apical dendritic branches, whereas cells $b$ and $c$ have somewhat longer branches either in layers 5 and $1($ cell $b)$ or layers 6,5 , and $4 C($ cell $c)$. Conventions are as in Figure 1. Scale bars, $100 \mu \mathrm{m}$.

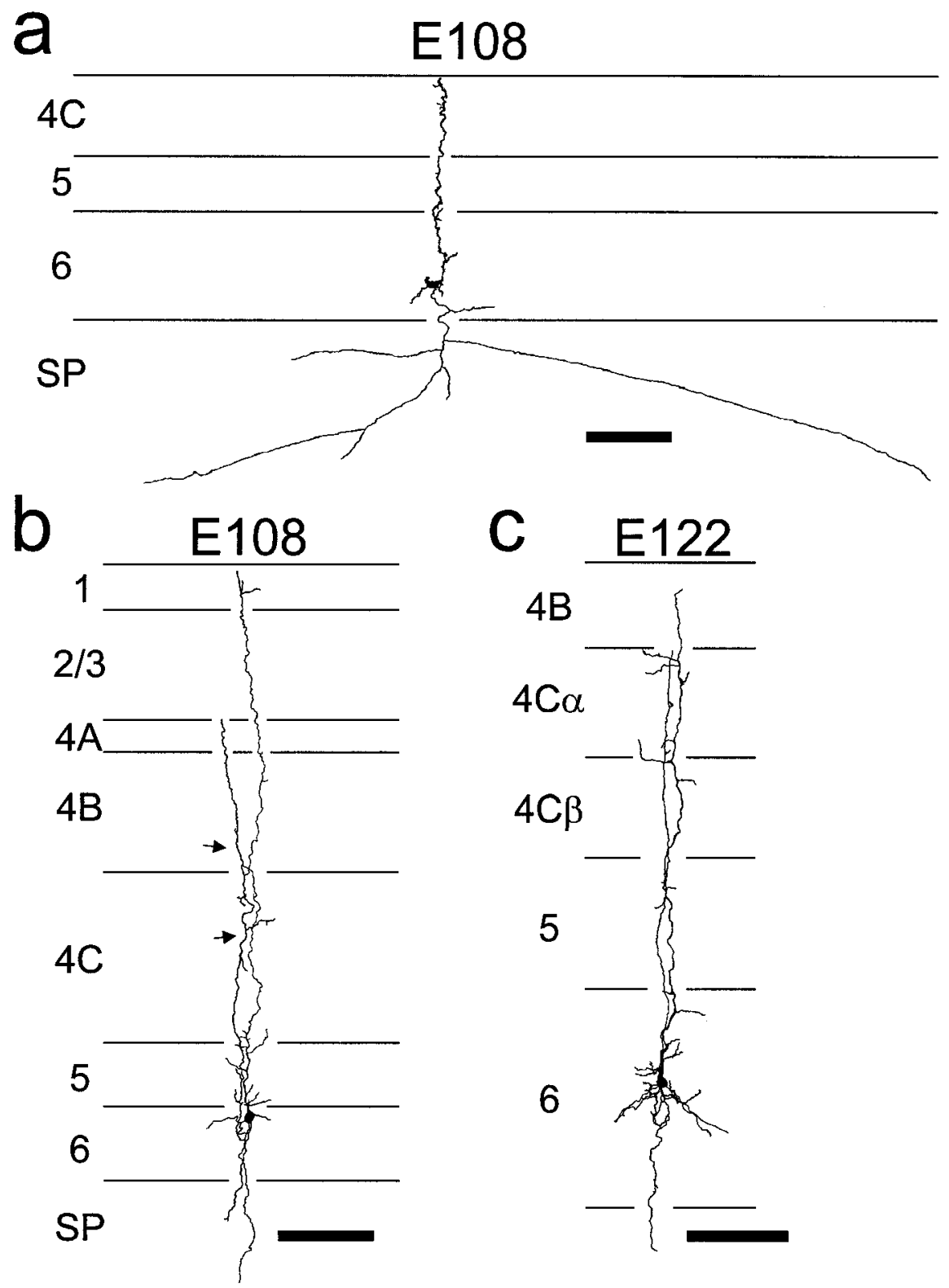

\section{Summary of developmental maturation of layer-specific axonal arbors}

During the time period studied (E100-E145), the axonal arbors of layer 6 pyramidal neurons gradually matured. Neurons initially lacked axonal branches, with the exception of branches in layer 6 that gave rise to predominantly unbranched recurrent collaterals, and branches in the subplate. Neurons with local, laterally projecting axons (presumptive type IIA) gradually increased the number and extent of their axonal branches in the deep layers, whereas those with recurrent collaterals gradually elaborated more extensive arbors in more superficial layers.

The development of these arbors was highly specific for the four main cortical layers from the outset. Presumptive class II neurons formed axonal arbors in superficial and/or deep layers but did not form axonal branches in layer 4C (Fig. 9). Presumptive class I neurons formed extensive axonal arbors in layer $4 \mathrm{C}$ but did not make axonal branches in layer 5 (Figs. 10-13). Cells with axonal branches in both layers $4 \mathrm{C}$ and 5 were not observed.
Furthermore, type IIA neurons formed their most extensive axonal arbors in deep layers (Fig. 9a), whereas type IIB neurons formed their arbors in superficial layers (Figs. $9 b, c$ ).

The development of sublaminar specificity, on the other hand, was not always specific from the outset. Presumptive type $\mathrm{I} \beta$ and I $\beta$ A neurons, located in the top of layer 6 (upper $40 \%$ ), formed their most extensive axonal arbors in layers $4 \mathrm{C} \beta$ and $4 \mathrm{~A} / 3 \mathrm{~B}$, but they often also formed exuberant axonal branches in layer $4 \mathrm{C} \alpha$ and/or had collaterals extending from $4 \mathrm{C} \beta$ into $4 \mathrm{C} \alpha$ or higher (Fig. 10).

The sublaminar specificity, within layer $4 \mathrm{C}$, of presumptive type I $\alpha$ neurons appeared to be somewhat more precise (Fig. 13). These cells, which were always located in the middle of layer 6 (depth of $40-60 \%$ ), formed extensive axonal arbors in layer $4 \mathrm{C} \alpha$ but did not form branches in $4 \mathrm{C} \beta$. However, they did extend numerous exuberant collaterals from layer $4 \mathrm{C} \alpha$ into and sometimes above layer 4B.

Other cells in the middle of layer 6 were presumptive type Im 

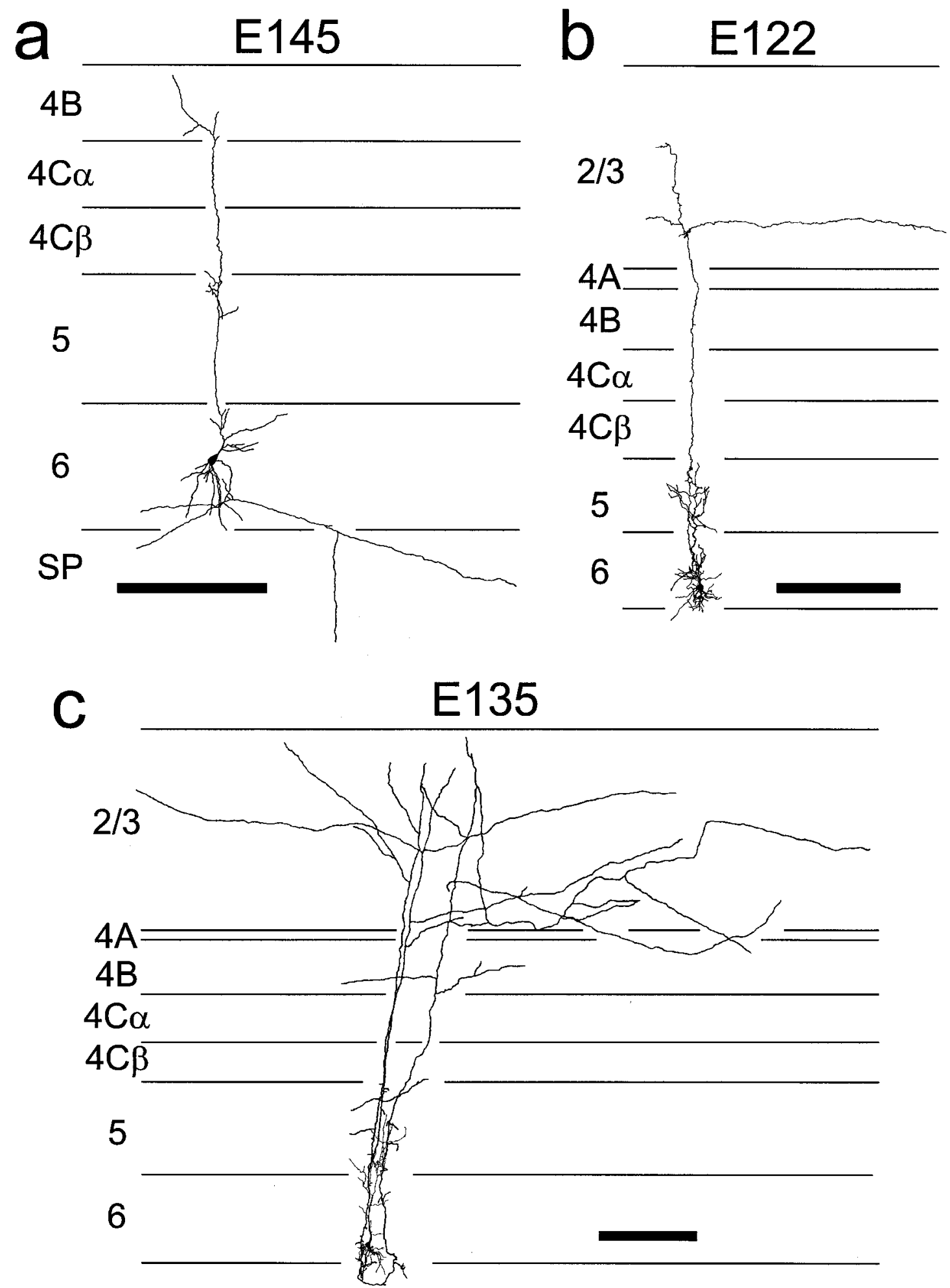

Figure 9. Layer 6 pyramidal neurons aged E145 $(a)$, E122 $(b)$, or E135 $(c)$. Cell $a$ has laterally projecting axon collaterals, projects to the subplate, and lacks a recurrent ascending axon collateral. It is, therefore, a presumptive type IIA neuron (see Results). This cell's apical dendrite extends up to layer $4 B$ and forms branches in layer 6 , upper layer 5 , and layer $4 B$. Cells $b$ and $c$ are presumptive type IIB layer 6 pyramidal neurons. They each have all the qualitative traits that are characteristic of mature type IIB neurons, but the axonal arbor of cell $b$ is relatively sparse, presumably an immature trait. These cells lack a descending axon and, instead, have recurrent ascending axon collaterals with short branches in layer 5 and much longer branches in layers $2-4 B$. The apical dendrites of the cells extend only to the top of layer 5 , and they branch extensively within layer 5 . The cell bodies are located at the bottom of layer 6 . Conventions are as in Figure 1. Scale bars, $200 \mu \mathrm{m}$. 

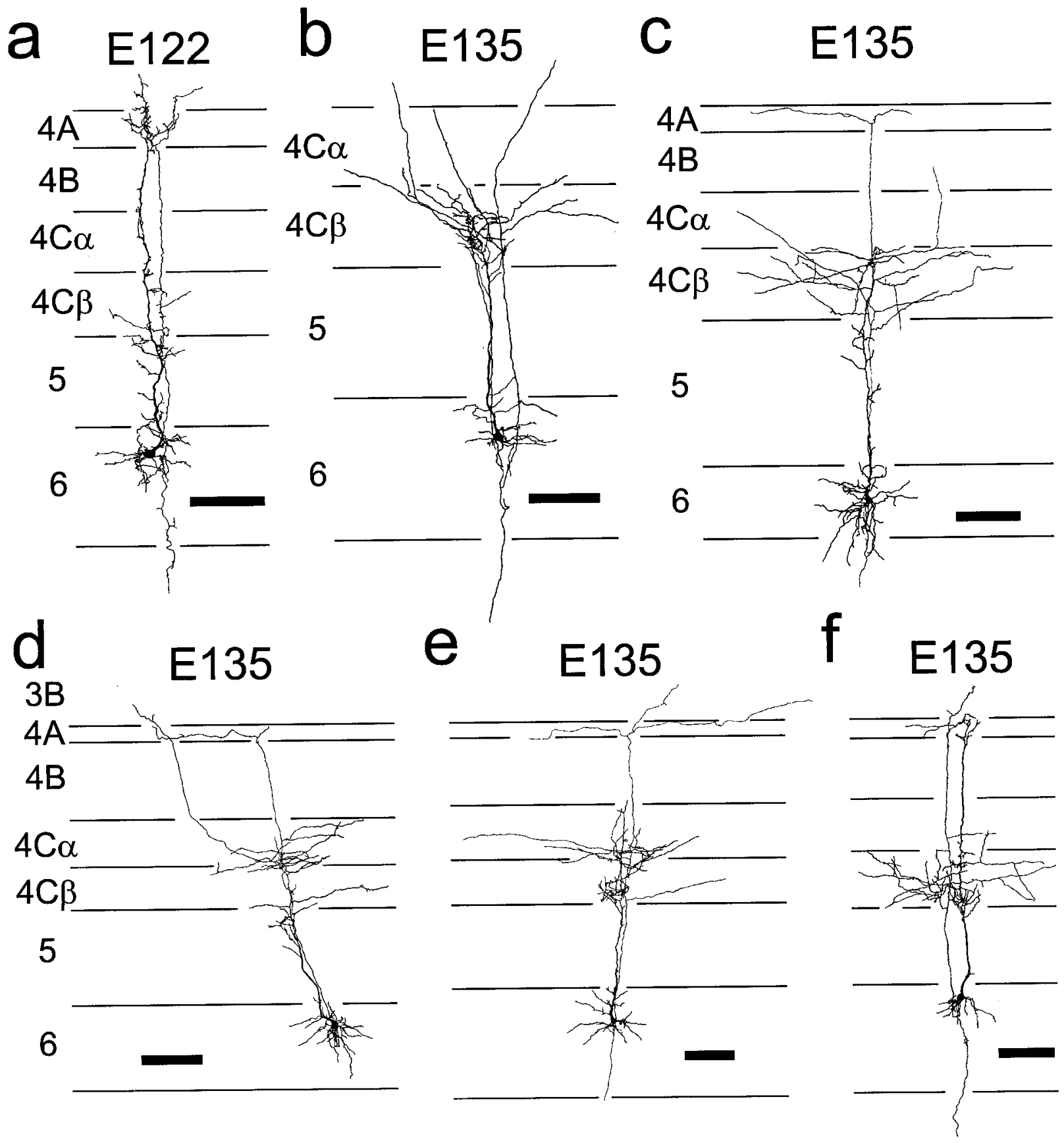

Figure 10. Presumptive type I $\beta(b)$ and I $\beta$ A $(a, c-f)$ layer 6 pyramidal neurons aged E122 $(a)$ or E135 $(b-f)$. All six neurons have cell bodies either in the upper $40 \%(a, b, d-f)$ or upper half $(c)$ of layer 6 and have recurrent ascending axon collaterals with branches in layer $4 C \beta$. Every cell except cell $d$ has a main descending axon extending into the white matter. Cell $a$ is the least mature and has only short lateral branches off its ascending axon collateral, but these are confined to the "correct" layers for a mature type I $\beta$ A neuron, layers $4 C \beta$ and $4 A$. Cell $c$ also confines its axonal branches to layers $4 C \beta$ and $4 A$, but "exuberant" collaterals extend into layers $4 C \alpha$ and $4 B$. Cell $b$ has similar exuberant collaterals, but it lacks an axon ascending to layer $4 A$, a characteristic of mature type $\mathrm{I} \beta$ neurons. The axonal branches of cell $f$ are also largely confined to layers $4 C \beta$ and $4 A$, but it has two branches at the bottom of layer $4 C \alpha$. Cells $d$ and $e$ both have axonal branches in layer $4 C \alpha$ and mid-layer $4 C$, in addition to branches in layers $4 C \beta$ and $4 A$. All six cells have apical dendritic branches in layers $5 A$ and $4 C \beta$, and cells $a$ and $f$ also have branches in layer $4 A$. Cell $a$ also has a dendritic branch in layer $4 C \alpha$. Conventions are as in Figure 1. Scale bars, $100 \mu \mathrm{m}$.

neurons (Fig. 12), and they did form exuberant axonal branches in lower layer $4 \mathrm{C} \beta$ as well as more extensive branches in the middle of layer $4 \mathrm{C}$ (in both $4 \mathrm{C} \alpha$ and $4 \mathrm{C} \beta$ ). Some of these cells also extended axons into layer $4 \mathrm{~B}$ or $4 \mathrm{~A}$. However, it cannot be ruled out that these were presumptive type I $\alpha$ cells with exuberant branches in layer $4 \mathrm{C} \beta$ or presumptive type $\mathrm{I} \beta$ or I $\beta \mathrm{A}$ cells with exuberant layer $4 \mathrm{C} \alpha$ branches.
Two groups of E100-E108 neurons: presumptive local, recurrent versus laterally projecting

At the earliest ages studied (E100 and E108), the axonal and dendritic arbors of layer 6 pyramidal neurons $(n=40)$ were extremely immature. The most striking properties of these cells were a paucity of local axonal arborization, descending axons that 
almost invariably extended into the white matter (37/39 cells, 1 ambiguous), and some cells with axonal branches in the subplate (10/40 cells).

However, despite their immaturity, these layer 6 pyramids could be clearly classified into two groups: those with an ascending, recurrent axon collateral branching off the main descending axon in layer 6 (Fig. $8 b$ ), and those that lacked an ascending collateral (Fig. $8 a$; see also above). The lack of an ascending collateral was highly correlated with the presence of axonal branches in the subplate. Twenty-eight of forty neurons had a single, recurrent axon collateral that originated from the main descending axon in layer 6 and rose above the cell body; only 1 of these 28 cells had an axonal branch in the subplate. In contrast, 9 of 12 neurons lacking an ascending collateral had subplate branches (Fig. 8a). In more mature cells with more extensive laterally projecting, local axonal arbors (see below), the presence of subplate branches continued to be correlated with a lack of ascending collaterals, typical of mature type IIA neurons (see above). These observations suggest that the layer 6 pyramids with axonal branches in the subplate at E100 and E108 might be presumptive type IIA neurons rather than presumptive class I or type IIB neurons that will later extend axons to the superficial layers.

The E100-E108 layer 6 pyramids with recurrent ascending axons extended their recurrent collateral, usually without branching, to varying levels. Only 3 cells extended an axon as high as layer 1 , but axons extending into layer $4 \mathrm{~B}$ or higher were common (17 cells). The ascending axon collaterals of the 11 remaining cells either ended or left the plane of the slice in layer $4 \mathrm{C}$ or lower. These rising collaterals either lacked branches (19/28 cells) or had branches that were extremely short $(<40 \mu \mathrm{m}$ long $)$ and sparse (Fig. $8 b$ ). When present, these short branches were most common in layer $2 / 3$ ( 6 cells) and less frequent in either layer $4 \mathrm{C} \alpha$ ( 2 cells) or layer 1 ( 1 cell). Of the 6 cells with layer $2 / 3$ branches, 1 also branched in layer 4B and another in layer 6 .

These branching patterns are compatible with those of numerous mature cells types (i.e., IIB, I $\alpha, \mathrm{I} \beta, \mathrm{I} \beta \mathrm{A}, \mathrm{Im}$, or IC) and, in view of their very short length, may not be particularly meaningful. For example, axonal branches in layer $2 / 3$ are consistent with class I types I $\beta$ A and IC, and with class II neurons. Also, types Im and $\mathrm{I} \alpha$ might have transient superficial axonal branches in prenatal neurons (see below). Furthermore, the axonal branching patterns were not correlated with distinctive patterns of dendritic branching or cell body depths suggestive of particular mature cell types.

\section{Presumptive type II A neurons}

As animals matured, the axonal arbors of presumptive type IIA layer 6 pyramidal neurons increased in length and complexity. However, their axonal arbors remained confined to layers 5 and 6 throughout the developmental period studied.

Of the 26 E122 layer 6 pyramids, 10 (38\%) lacked recurrent ascending axon collaterals. This proportion is as large as the E100-E108 value (30\%, 12/40 cells), consistent with the possibility that the cells lacking ascending collaterals at the earlier age do not form them later (see above). By E122 these cells typically had horizontal axon collaterals in layer 6 (8/10 cells) that were not observed in the cells with recurrent ascending axons ( $0 / 16$ cells). They are therefore presumptive type IIA neurons. Like less mature presumptive type IIA neurons, 4 of 10 of these cells had axonal branches in the subplate, whereas none with ascending axons had subplate branches. All of these presumptive type IIA neurons extended their descending axon into the white matter ( $8 / 8$ cells, 2 ambiguous).

The apical dendrites of the presumptive type IIA, E122 cells typically extended into layers $2-4 \mathrm{~B}$, with only 1 stopping in layer 4C and 1 extending to layer 1 . Most cells (6/10) had apical dendritic branches in both layers 5 and 6 . Two of these cells also had more superficial apical dendritic branches; these were located in layers $2-4 \mathrm{~B}$ for 1 cell and in layer $4 \mathrm{C}$ for the other. Two other cells also had apical dendritic branches in layer 4C, but 1 lacked branches in layer 6 and the other lacked them in both layers 5 and 6. Finally, 1 cell had apical dendritic branches only in layer 6 and another only in layer 5. All of these patterns of apical dendritic arborization are consistent with observations of postnatal neurons (Wiser and Callaway, 1996, 1997).

At E135, only 2 of 19 layer 6 pyramidal neurons lacked a recurrent ascending axon collateral. These cells both had long, laterally projecting axonal branches in layer 6 and, therefore, are presumptive type IIA neurons. In addition, both cells projected their main descending axon into the white matter and had axonal branches in the subplate, further supporting a link between these presumptive type IIA cells and less mature neurons with subplate branches but no recurrent axon collaterals. No other E135 layer 6 pyramids had axonal branches in the subplate (but 1 was ambiguous). The apical dendrites of both presumptive type IIA neurons extended up to layer $4 \mathrm{~B}$ and branched in layers 5 and 6; 1 also had dendritic branches in layer 4B.

Presumptive type IIA neurons at E145 were similar to those at E135. Five of sixteen E145 layer 6 pyramids had long, lateral axonal branches and no ascending, recurrent axon collateral (Fig. $9 a$ ). One of these was the only E145 cell with axonal branches in the subplate. Again, all of the presumptive type IIA neurons projected to the white matter ( $4 / 4$ cells, 1 ambiguous). The apical dendrites of all of these neurons extended into layers 2-4B (4/4 cells, 1 truncated in layer $4 \mathrm{C}$ ) and formed branches in layers 2-4B, 5, and 6 (Fig. 9a). No apical dendritic branches were detected in layer $4 \mathrm{C}$. The apical dendrite of 1 of the cells extended into layer 1.

\section{Presumptive type IIB neurons}

The axonal arbors of presumptive type IIB neurons developed with precise laminar specificity from the outset. Axonal branches were confined to the correct layers, 2-4B and 5, but not layer 4C, even in the youngest cells. Also, as in mature cells, the length of axons in layers $2-4 \mathrm{~B}$ was substantially greater than in layer 5 throughout their maturational history.

For the least mature cells in our sample (E100, E108, and some E122), presumptive type IIB neurons could not be distinguished from other layer 6 pyramids with recurrent, ascending axons collaterals. This is because of the paucity and short length of secondary axonal branches emerging from the recurrent collaterals in more superficial layers (Fig. 8). At E122, 4 of the 16 layer 6 pyramids with recurrent axon collaterals lacked further branches, precluding further grouping (Fig. $8 c$ ). Another cell was ambiguous, despite axonal branches off the recurrent collateral, because these were found only in layer $4 \mathrm{~A}$. Branches in this layer are consistent with types I $\beta$ A or IC as well as type IIB.

One E122 neuron with a recurrent axon collateral was a presumptive type IIB neuron (Fig. 9b). This cell had nearly all of the traits of a mature type IIB neuron. It was located deep in layer 6, and its apical dendrite did not extend above layer 5 and had several branches within layer 5. Furthermore, its recurrent ascending axon collateral had short branches in layer 5 and longer, 


8
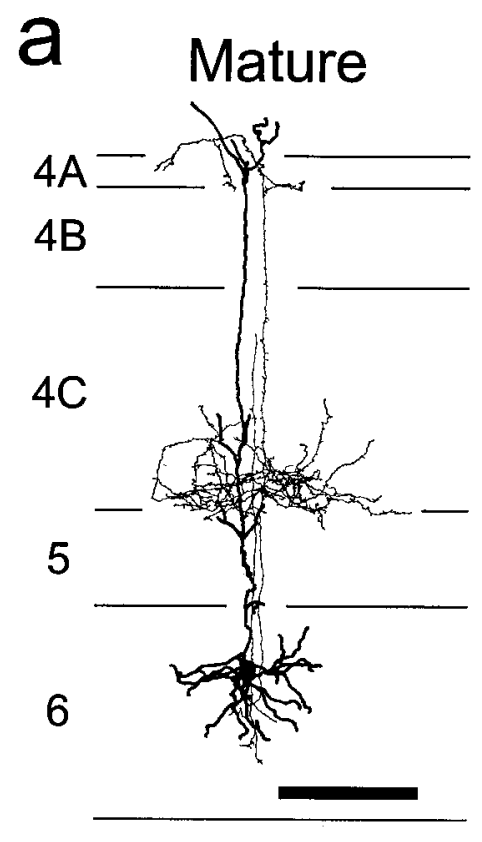

b

Mature

Figure 11. Examples of mature type I $\beta$ A $(a)$ and type $\mathrm{I} \beta(b)$, layer 6 pyramidal neurons. The type I $\beta$ A neuron has two recurrent ascending axon collaterals extending to layer $4 C$ and forming an extensive arbor in layer $4 C \beta$. One of the ascending collaterals also extends to and branches in layer $4 A$. The apical dendrite extends to layer $4 A$ and branches in layers $4 A, 4 C \beta$, and the top of layer 5 . The type $\mathrm{I} \beta$ neuron $(b)$ also has a recurrent ascending axon arborizing in layer $4 C \beta$, but lacks axons above layer $4 C \beta$. Similarly, the apical dendrite confines its branches to layer $4 C \beta$ and upper layer 5 , and it does not extend above layer $200 \mu \mathrm{m}$. From Wiser and Callaway (1996).

lateral branches in layer 2/3. However, this cell did extend a descending axon into the white matter.

At E135, 4 of 19 layer 6 pyramids were presumptive type IIB cells with all of the traits that are characteristic of mature type IIB neurons (Fig. 9c). Two other presumptive type IIB neurons were atypical. They had axonal arbors like type IIB neurons and, therefore, are assigned to this group, but their dendritic arbors and cell body locations were different. Similarly, of 2 presumptive E145 type IIB neurons, 1 had virtually all of the adult traits whereas the other had the same traits as the atypical type IIB neurons observed at E135.

A typical type IIB neuron, representative of the 5 observed at E135 and E145, is illustrated in Figure 9c. These cells all had recurrent ascending axon collaterals that gave off relatively short collaterals in layer 5 and numerous longer axon collaterals in layers 2-4B; they did not project to the white matter. All of their cell bodies were located deep in layer 6 , and their apical dendrites had numerous branches throughout layer 5. The apical dendrites of the 4 E135 cells did not extend above layer $4 \mathrm{C} \beta$, whereas the E145 cell was unusual in that its apical dendrite extended to and branched in layer $4 \mathrm{~B}$.

The 3 atypical, presumptive type IIB neurons at E135-E145 all had the same anatomical features. Like typical type IIB neurons, they lacked a projection to the white matter and had recurrent ascending axon collaterals that extended to layer 2, giving off short lateral branches in layer 5 and longer branches in layers 2-4B. However, unlike typical type II B neurons, these cells were located in the upper $40 \%$ of the depth of layer 6 and had apical dendrites extending to layer 4B or higher, with branches in layers $4 \mathrm{~B}$ and 5.

\section{Presumptive type I $\beta$ and I $\beta A$ neurons}

Presumptive type $\mathrm{I} \beta$ and $\mathrm{I} \beta \mathrm{A}$ neurons developed dense axonal arbors in layer $4 \mathrm{C} \beta$ and sometimes (type I $\beta \mathrm{A}$ ) sparse arbors in layer 4A, but they never had axonal branches in layer 5. However, they did form presumed transient axonal branches in an incorrect sublayer, layer $4 \mathrm{C} \alpha$. They also extended exuberant axon collaterals obliquely into layers $4 \mathrm{C} \alpha$ and $4 \mathrm{~B}$ (see Fig. 15 for a summary schematic).
A total of 16 presumptive type $\mathrm{I} \beta$ and $\mathrm{I} \beta \mathrm{A}$ neurons were identified in slices from the E122, E135, and E145 animals (Fig. $10)$. These cells were characterized by axonal branches in layer $4 \mathrm{C} \beta$ (type $\mathrm{I} \beta$, e.g., Fig. $10 b$ ) or both layers $4 \mathrm{C} \beta$ and $4 \mathrm{~A} / 3 \mathrm{~B}$ (type $\mathrm{I} \beta \mathrm{A}$, e.g., Fig. $10 a, c-f)$. However, many of these cells also had features not found in mature type I $\beta$ or I $\beta$ A cells. These features included axonal and or dendritic branches in layer $4 \mathrm{C} \alpha$ and axonal branches originating in layer $4 \mathrm{C} \beta$ and extending obliquely through layer $4 \mathrm{C} \alpha$. All of these cells were located in the upper half of layer 6 , and 12 of 16 were located in the upper $40 \%$ of the layer. Because, in postnatal animals, type $\mathrm{I} \beta$ and $\mathrm{I} \beta \mathrm{A}$ neurons are the only class I cells located in the upper $40 \%$ of layer 6 (Wiser and Callaway, 1996), it is presumed that the axonal and dendritic branches originating in or extending through layer $4 \mathrm{C} \alpha$ are immature features of these cell types.

I have distinguished between presumptive type $\mathrm{I} \beta \mathrm{A}$ and $\mathrm{I} \beta$ cells based on the presence or absence of recurrent axon collaterals rising to layer $4 \mathrm{~A}$. These are the same criteria that have been used for mature cells. It is possible, however, that some presumptive type I $\beta$ A neurons will mature into type I $\beta$ neurons by eliminating axon collaterals projecting to layer $4 \mathrm{~A}$. This possibility is supported by the observation that some presumptive type $\mathrm{I} \alpha$ and $\mathrm{Im}$ neurons have superficial axonal projections, whereas these are not found in their mature counterparts (see below).

Two presumptive type I $\beta \mathrm{A}$ and two presumptive type $\mathrm{I} \beta$ neurons were sampled at E122 (Fig. 10a). All of these cells projected their main descending axon into the white matter. The presumptive type I $\beta$ A neurons each had a recurrent axon collateral extending into layer 3 and several axonal branches in layer $4 \mathrm{C} \beta$. One of the cells (Fig. 10a) also formed axonal branches in layer 4A. Neither cell had "incorrect" axonal branches in layers 5, $4 \mathrm{C} \alpha$, or $4 \mathrm{~B}$. Both cells also had apical dendritic branches in layer $4 \mathrm{C} \beta$, and the cell with axonal branches in layer 4A also had apical dendritic branches in layer 4A. However, each cell also had an "incorrect" dendritic branch in layer $4 \mathrm{C} \alpha$.

The 2 E122 presumptive I $\beta$ cells did not project axons above layer $4 \mathrm{C}$, and both had several axonal branches in layer $4 \mathrm{C} \beta$ 

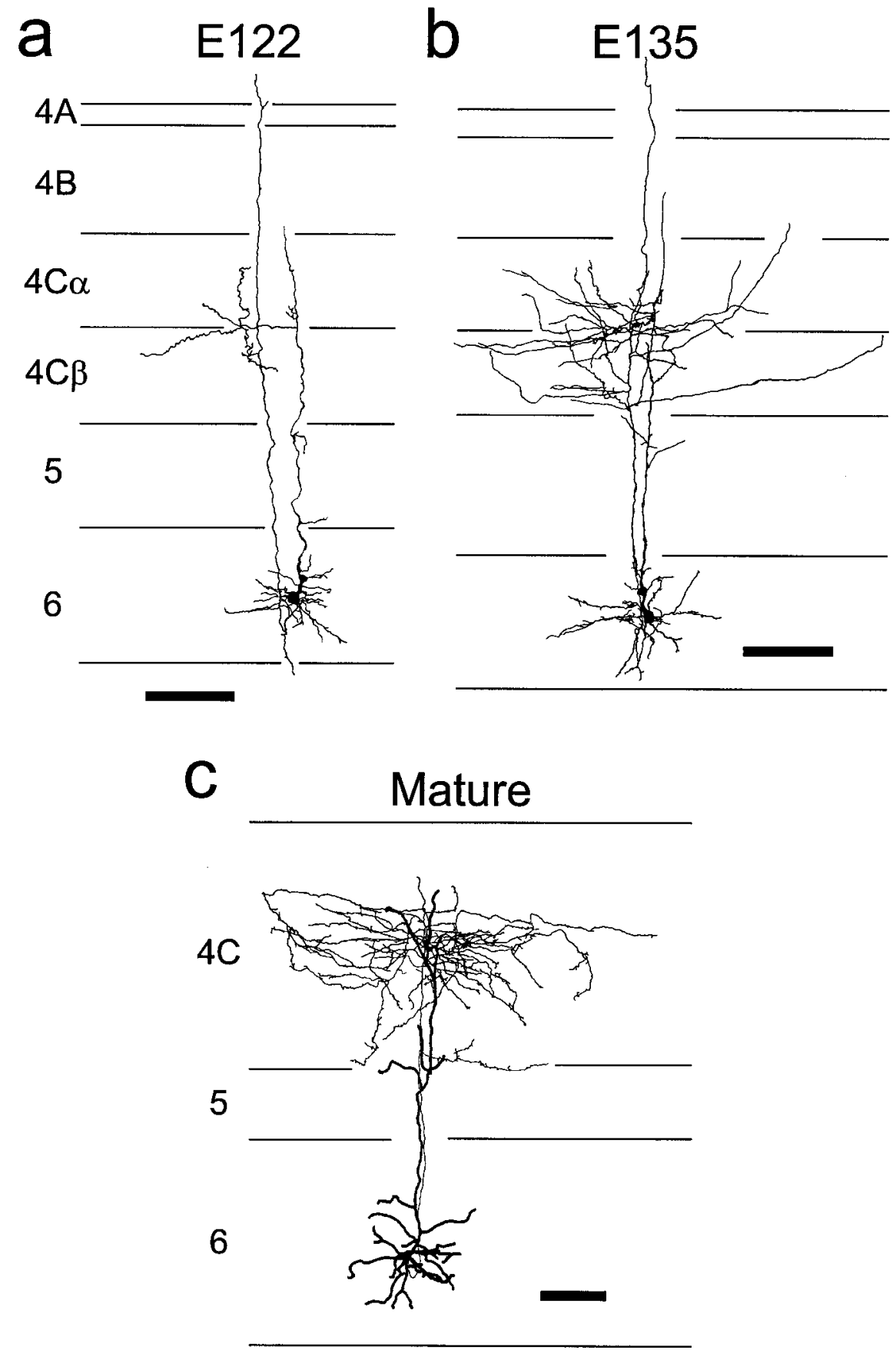

Figure 12. Mature $(c)$ and presumptive type Im layer 6 pyramidal neurons aged E122 $(a)$ or E135 (b). All three neurons have cell bodies in the middle of layer 6 (depths of 40-60\%). Cell $a$ has a descending axon extending to the white matter and a recurrent ascending axon extending up to layer $3 B$. The ascending axon branches in the middle of layer $4 C$ and in layer $4 A$. The apical dendrite of cell $a$ extends to the layer $4 B$ /layer $4 C$ border and has short branches at the bottom of layer $4 C \alpha$ and the top of layer 5 . Cell $b$ lacks a descending axon but has a recurrent ascending axon extending to layer $3 B$. Along the way, it gives off branches in layers $4 C \beta$ and $4 C \alpha$. They are most dense at the middle of layer $4 C$, but many are also found at the bottom of layer $4 C \beta$. Some layer $4 C \beta$ branches extend obliquely into layers $4 C \alpha$ and $4 B$. The apical dendrite extends to the top of layer $4 C \beta$ before leaving the plain of the brain slice and has branches in layers 5 and $4 C \beta$. Like presumptive type Im neurons, mature neurons $(c)$ have their most dense axonal arbors in the middle of layer $4 C$. But unlike prenatal neurons, they lack axonal projections above the middle of layer $4 C$ or to the white matter. And axonal branches in layer $4 C \beta$ are very sparse. Mature type Im apical dendrites extend only as high as layer $4 C$, and they branch in the middle of layer $4 C$ and in upper layer 5 . Conventions are as in Figure 1. Scale bars, $100 \mu \mathrm{m}$. Panel $c$ is from Wiser and Callaway (1996). comparable with those illustrated in Figure 10a. The axonal arbor of 1 of the cells was highly specific for layer $4 \mathrm{C} \beta$, lacking axons extending into or branching in layer $4 \mathrm{C} \alpha$, but the other cell had exuberant axon collaterals in layer $4 \mathrm{C} \alpha$. These included branches off the main recurrent collateral within layer $4 \mathrm{C} \alpha$ as well as branches that originated in layer $4 \mathrm{C} \beta$ and extended obliquely into $4 \mathrm{C} \alpha$ (see, for example, Fig. 10b,c). Both of these cells also had apical dendrites extending into layer $4 \mathrm{~B}$ and branching in layer $4 \mathrm{C} \alpha$ as well as $4 \mathrm{C} \beta$.

Seven of the nineteen layer 6 pyramids sampled at E135 were presumptive type I $\beta$ or I $\beta A$ neurons. Six of these were presumptive type I $\beta$ A neurons, and each, like mature type I $\beta$ A cells, had substantial axonal arbors in layer $4 \mathrm{C} \beta$ as well as ascending collaterals branching in layer $4 \mathrm{~A}$ (Fig. $10 c-f$ ). Two of these (not shown) lacked axonal branches in any other layers, but they did have "exuberant" apical dendritic branches in layer $4 \mathrm{C} \alpha$.

The remaining four presumptive type I $\beta$ A neurons all had exuberant axon collaterals in layer $4 \mathrm{C} \alpha$ (Fig. 10c-f). For 1 cell (Fig. $10 c$ ), these consisted simply of collaterals extending obliquely into layer $4 \mathrm{C} \alpha$ from layer $4 \mathrm{C} \beta$. However, for the remaining three cells, axon collateral branches emerged from the main ascending collateral within layer $4 \mathrm{C} \alpha$. These could be substantial (Fig. 10d,e) or sparse (Fig. 10f). One of these four cells had apical dendritic branches only in layers 4A, 4C $\beta$, and 5A (Fig. 10f), 2 had an apical dendrite that only extended up to layer $4 \mathrm{C} \alpha$ and branched in layer $4 \mathrm{C} \alpha$ as well as $4 \mathrm{C} \beta$ (Fig. 10d,e), and the last only extended its apical dendrite up to and branched in layer $4 \mathrm{C} \beta$ (Fig. 10c).

All 6 of the E135 presumptive type I $\beta$ A neurons had their cell 
Figure 13. Mature (e) and presumptive type I $\alpha$ layer 6 pyramidal neurons aged E122 $(a, b)$, E135 $(c)$, or E145 $(d)$. All five neurons have cell bodies in the middle of layer 6 (depths of $40-60 \%$ ). The prenatal neurons all have main descending axons that extend into the white matter and recurrent ascending collaterals extending up to layer $3 B(a$, $c), 4 B(b)$, or the top of $4 C(d)$. The ascending axon collaterals all have branches in layer $4 C \alpha$ but not $4 C \beta$. These are sparse for the E122 cells $(a, b)$ but extensive for older cells $(c, d)$. Axons extending obliquely from layer $4 C \alpha$ into layer $4 B$ are common $(b, c)$. The apical dendrites of cells $a$ and $c$ only extend as high as layer $4 C \alpha$ and have branches in layers $4 C \alpha$ and upper layer 5. However, the apical dendrites of cells $b$ and $d$ extend into layer $3 B$ and have branches in layer $4 B$ (open arrow in $d$ ). The filled arrow in $d$ indicates axonal branches extending into layer $4 C \alpha$ from layer $4 C \beta$. In contrast to prenatal neurons, mature type I $\alpha$ neurons $(e)$ do not extend their axons or apical dendrites above layer $4 C$ and lack axonal projections to the white matter. They are similar, however, in that they do have extensive axonal arbors in layer $4 C \alpha$ and apical dendritic branches in layer $4 C \alpha$ and upper layer 5. Conventions are as in Figure 1. Scale bars, $100 \mu \mathrm{m}$. Panel $e$ is from Wiser and Callaway (1997).

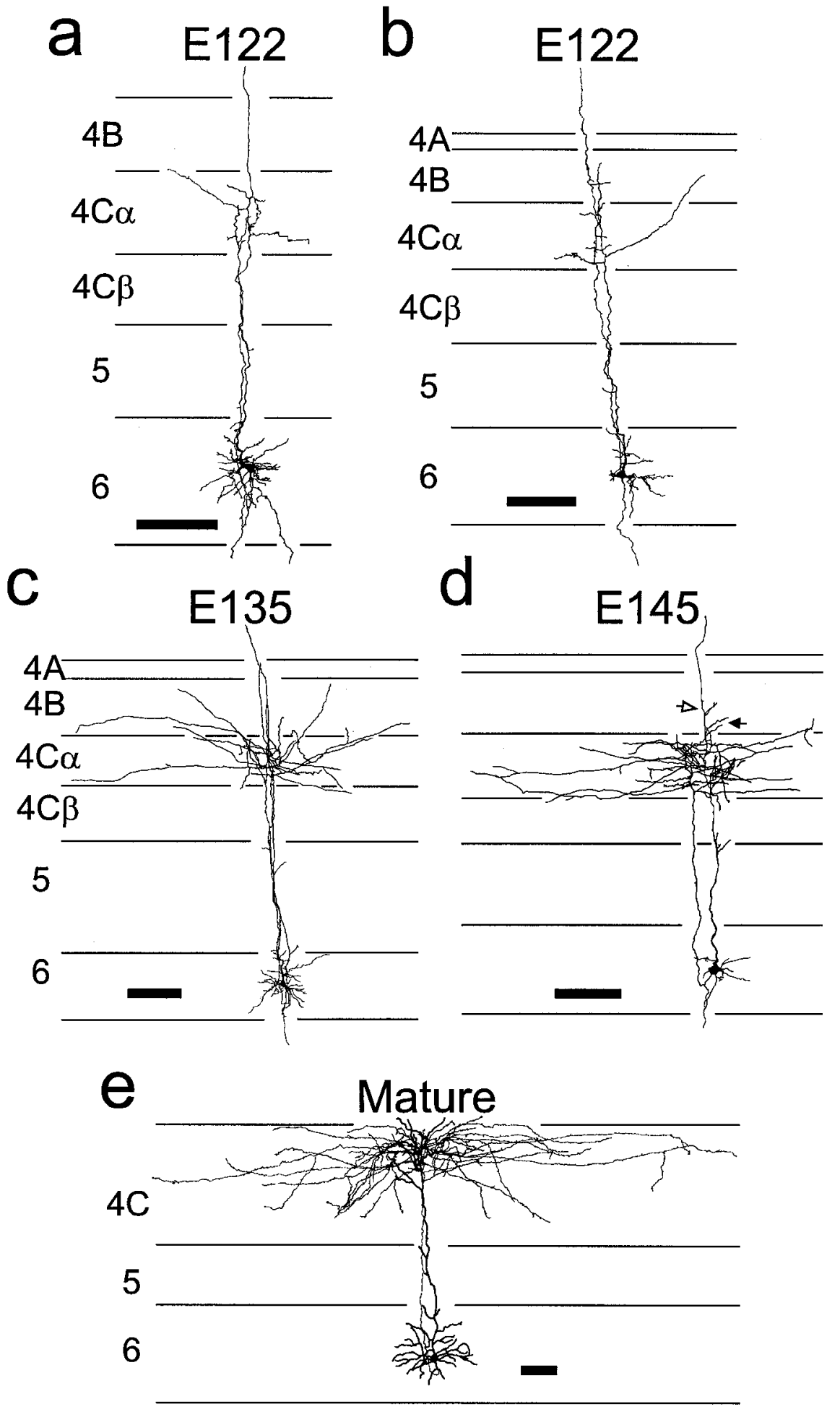

bodies in the upper half of layer $6 ; 5$ were in the upper $40 \%$ of the layer, but 1 was in the middle (Fig. 10c) and, therefore, could be in theory a presumptive I $\alpha$ or Im neuron. This seems unlikely, however, in view of the dense axonal arbor in layer $4 \mathrm{C} \beta$ and relatively sparse axons in layer $4 \mathrm{C} \alpha$. Two other cells had surprisingly dense axonal arbors in the middle of layer $4 \mathrm{C}$ or in $4 \mathrm{C} \alpha$ relative to their layer 4C $\beta$ arbors (Fig. 10d,e), suggesting that they could be presumptive type I $\alpha$ or Im neurons. However, their cell body positions in the upper $40 \%$ of layer 6 are inconsistent with this classification.
Furthermore, if these were assigned to the $\mathrm{I} \alpha$ or $\mathrm{Im}$ categories, their axonal arbors in lower layer $4 \mathrm{C} \beta$ and in layer $4 \mathrm{~A}$ would have to be considered exuberant. Five of the six presumptive I $\beta$ A cells projected their main descending axon to the white matter (the cell without a projection is shown in Fig. 10d).

The only presumptive type I $\beta$ neuron at E135 is shown in Figure $10 b$. Its cell body is in upper layer 6 , and it projects to the white matter. The cell's apical dendrite rises only to layer $4 \mathrm{C} \beta$, where it forms several branches. The ascending recurrent axon 


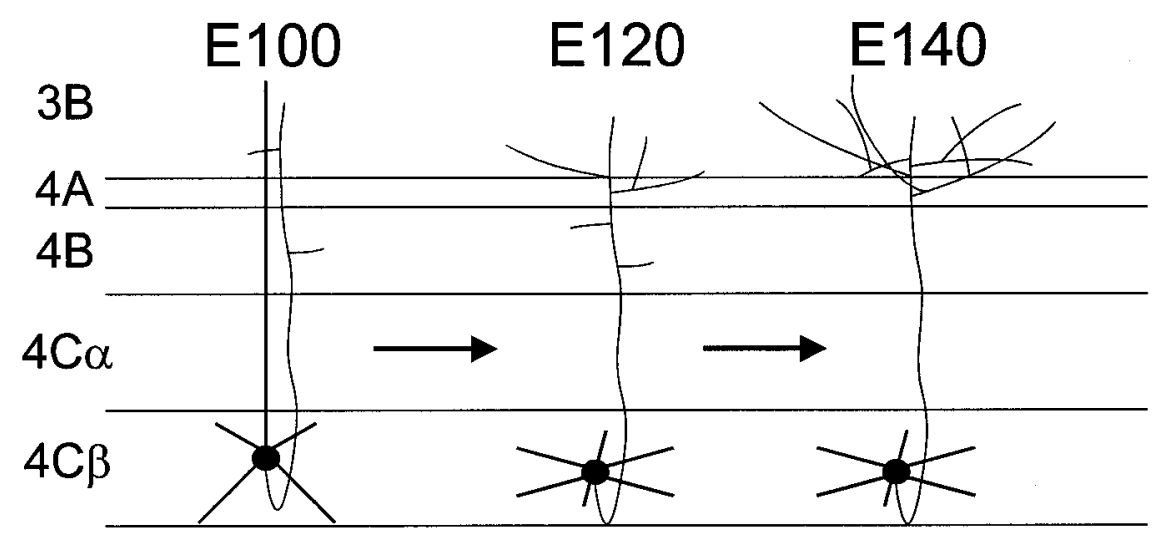

Figure 14. Summary of possible developmental changes in axonal and dendritic arbors of layer $4 \mathrm{C} \beta$ spiny neurons as suggested by observations of intracellularly labeled neurons. At $\sim$ E100 (far left), layer $4 C \beta$ spiny neurons already extend recurrent axons into layer 3 . These axons have short branches in layers 3 and $4 B$. At this age, these cells have a prominent apical dendrite. By $\sim \mathrm{E} 120$ (middle), the apical dendrites are either shorter or gone and layer $4 C \beta$ cells have a spiny stellate morphology. The recurrent ascending axon now arborizes more extensively in the "correct" layers, $4 A$ and $3 B$, but for some cells, presumably transient branches are still found in layer $4 B$. By $\sim$ E140 (right), the extent of axonal arborization in layers $4 A$ and $3 B$ is similar to that in mature cells, and layer $4 B$ branches are not detected. Filled ovals indicate cell bodies, and thick and thin lines indicate dendrites and axons, respectively. Other conventions are as in Figure 1. collateral also branches in layer $4 \mathrm{C} \beta$, but not $4 \mathrm{C} \alpha$. Several of the axonal branches originating in layer $4 \mathrm{C} \beta$ extend exuberantly into layer $4 \mathrm{C} \alpha$ or even to layer $4 \mathrm{~B}$, but none extends to layer $4 \mathrm{~A}$.

Five presumptive type I $\beta$ A neurons were labeled in E145 slices. These were all located in the upper half of layer 6 , with 1 of 5 located in the middle fifth of the layer (depth of 45\%). All 5 also extended their main descending axon into the white matter. The laminar specificities of the axonal and dendritic arbors of these cells were all similar to those observed in mature type I $\beta \mathrm{A}$ neurons. They all formed axonal arbors in layers $4 \mathrm{C} \beta$ and $4 \mathrm{~A} / 3 \mathrm{~B}$ and lacked axonal branches in layer $4 \mathrm{C} \alpha$. Three of five cells extended their apical dendrite into layer 3 and had dendritic branches in layers $4 \mathrm{C} \beta$ and $4 \mathrm{~A} / 3 \mathrm{~B}$. The remaining 2 cells both had dendritic branches in layer $4 \mathrm{C} \beta$, but 1 extended its apical dendrite only as high as layer $4 \mathrm{C} \alpha$ and the other's apical dendrite was truncated in layer $4 \mathrm{C} \beta$.

\section{Presumptive type I $\alpha$ and Im neurons}

Presumptive type I $\alpha$ and type Im neurons, like other presumptive class I neurons, formed extensive axonal arbors in layer $4 \mathrm{C}$ but not in layer 5 . For the type I $\alpha$ neurons, axonal branching in layer $4 \mathrm{C}$ was confined to the layer $4 \mathrm{C} \alpha$ subdivision at all ages studied. Nevertheless, the recurrent ascending axons of these cells extended into layer $2 / 3$ and branches originating in layer $4 \mathrm{C} \alpha$ extended exuberantly into layer 4B (see Fig. 15 for a summary schematic). Presumptive type Im neurons also had exuberant projections superficial to layer 4C. In addition, their arbors within layer $4 \mathrm{C}$ were less precise than those of type I $\alpha$ neurons. Most of the axonal branches formed correctly, in the middle of layer $4 \mathrm{C}$, but many of these extended exuberantly into the upper third of layer $4 \mathrm{C}$. Branches at the bottom of layer $4 \mathrm{C} \beta$ also appeared to be more common than in maturity (see Fig. 15 for a summary schematic).

A total of 14 presumptive type I $\alpha$ and Im layer 6 pyramidal neurons were labeled in slices from E122 and older animals. All of these neurons had cell bodies in the middle of layer 6 (depths of 40-60\%). Presumptive type Im neurons were distinguished from type $\mathrm{I} \alpha$ by the presence of axonal branches in layer $4 \mathrm{C} \beta$ (compare Fig. $11 b$ with Fig. 12) and from both types $\mathrm{I} \beta \mathrm{A} / \mathrm{I} \beta$ and $\mathrm{I} \alpha$ by relatively dense axonal arbors in the middle of layer $4 \mathrm{C}$, near the $4 \mathrm{C} \alpha / 4 \mathrm{C} \beta$ border. They were also distinguished from $\mathrm{I} \beta \mathrm{A} / \mathrm{I} \beta$ by having cell bodies in the middle of layer 6 rather than the upper $40 \%$ (compare Fig. $11 b$ with Fig. 10d,e). It cannot be ruled out that presumptive type Im neurons actually might be destined to become type I $\alpha$ neurons by the elimination of axonal arbors in layer $4 \mathrm{C} \beta$, or become type $\mathrm{I} \beta$ or $\mathrm{I} \beta \mathrm{A}$ neurons by the elimination of arbors in layer $4 \mathrm{C} \alpha$. However, they are not presumptive type IC neurons, because mature type IC neurons are only found deep in layer 6 (Wiser and Callaway, 1996).

Of the 26 layer 6 pyramids sampled at E122, 5 were presumptive type I $\alpha$ neurons (Fig. 12a,b) and 1 was a presumptive type Im neuron (Fig. 11a). Unlike mature type Im and I $\alpha$ neurons, all 6 of these cells projected an axon to the white matter and they also all extended their main recurrent ascending axon above layer $4 \mathrm{C}$ (Figs. 11a, 12a,b). The presumptive type I $\alpha$ cells all confined their branches off the recurrent ascending axon to layer $4 \mathrm{C} \alpha$; none was present in either layer $4 \mathrm{C} \beta$ or $4 \mathrm{~B}$ (Figs. 12a,b). Two of these cells extended one or more exuberant axon collaterals obliquely into layer $4 \mathrm{~B}$ from their origin in layer $4 \mathrm{C} \beta$ (Fig. 12b).

The E122 presumptive type Im neuron is illustrated in Figure 11a. It projected its main descending axon into the white matter and had a single recurrent ascending axon collateral extending "exuberantly" to and branching in layer 4A. It also had axonal branches in the middle of layer 4C. Its apical dendrite extended to the top of layer $4 \mathrm{C}$ and branched in the bottom of layer $4 \mathrm{C} \alpha$, in layer $5 \mathrm{~A}$, and at the layer $5 /$ layer 6 border.

Four presumptive type $\mathrm{I} \alpha$ and Im neurons were sampled at E135 (Figs. $11 b, 12 c$ ). One of two presumptive type I $\alpha$ neurons projected to the white matter (Fig. 12c), whereas 1 of the 2 presumptive type Im cells lacked a projection to the white matter (Fig. 11b) and the other was ambiguous because of truncation of a descending axon in layer 6 . Both of the presumptive type I $\alpha$ neurons had recurrent ascending axon collaterals that branched exclusively in layer $4 \mathrm{C} \alpha$, but many of these extended exuberantly into layer 4B (Fig. 12c). The apical dendrite of one of these cells extended to the top of layer $4 \mathrm{C}$ and branched in layers $4 \mathrm{C} \alpha$ and 5A (Fig. 12c). The other cell's apical dendrite was truncated in lower layer $4 \mathrm{C} \alpha$ before giving rise to any branches.

The E135 presumptive type Im neurons both extended a recurrent ascending axon collateral into layer 3 that formed an axonal arbor predominantly in the middle of layer 4C (Fig. 11b). They both also had a smaller number of exuberant axonal branches at the bottom of layer $4 \mathrm{C} \beta$. One of these cells had an axonal branch in layer $4 \mathrm{~A}$ and none in the middle of layer $4 \mathrm{C} \beta$, giving it an appearance similar to the presumptive type I $\beta$ A cells illustrated in Figure 10, $d$ and $e$. It differed from these cells only in that its cell body was located deeper in layer 6 . The other cell had more axon collaterals in the middle of layer $4 \mathrm{C} \beta$ (Fig. 11b). 


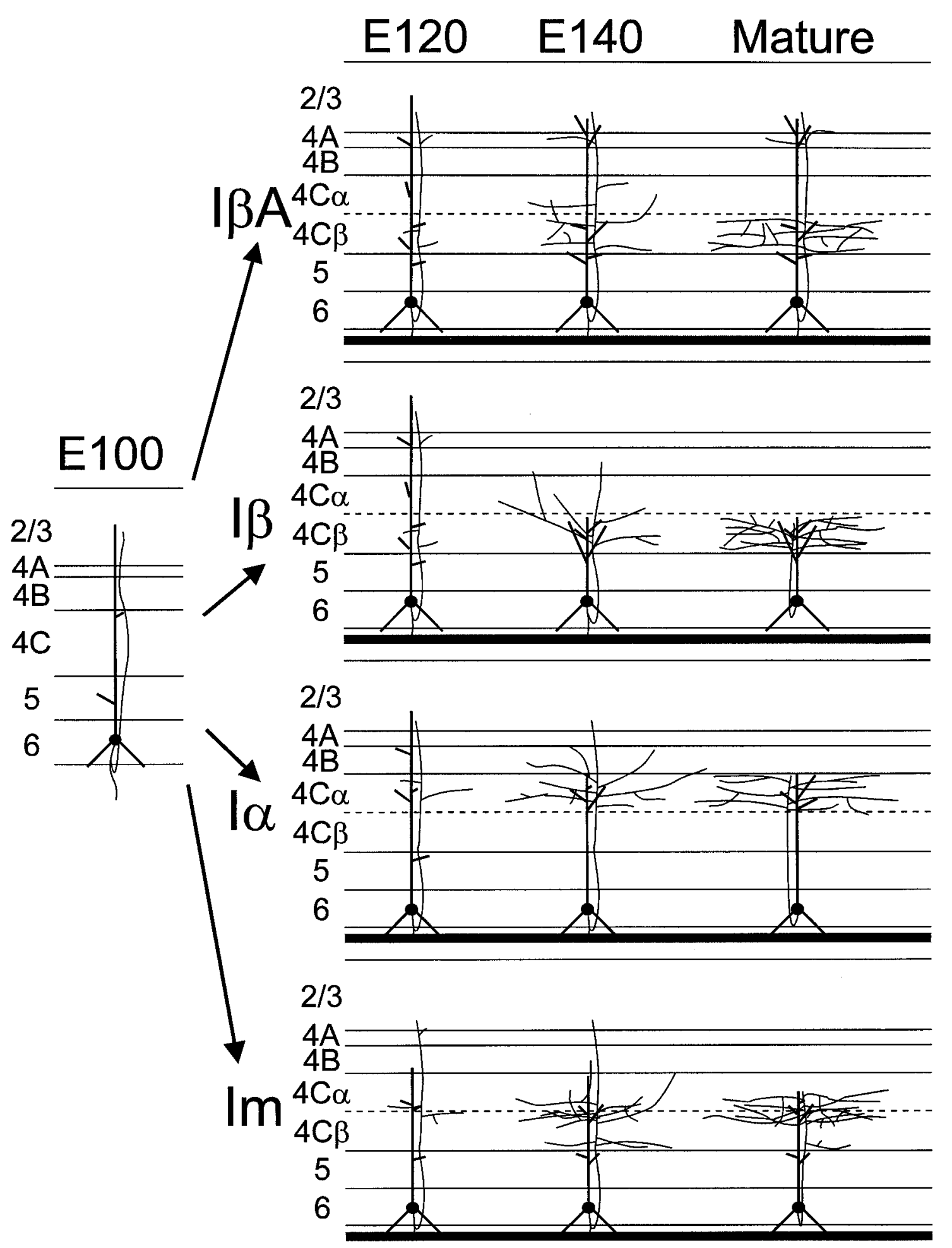

Figure 15. Summary of possible developmental changes in axonal and dendritic arbors of class I, layer 6 pyramidal neurons, as suggested by observations of intracellularly labeled neurons. At E100 ( far left), recurrent ascending axons of layer 6 pyramidal neurons extend into layer $2 / 3$ but lack branches. By $\sim$ E120, the laminar patterns of branching from the recurrent ascending axons are suggestive of presumptive fates. At this age, all four types of presumptive class I, layer 6 pyramidal neurons (I $\beta$ A, I $\beta, \mathrm{I} \alpha$, and $\mathrm{Im}$; illustrated from top to bottom, respectively) have recurrent axon collaterals and apical dendrites ascending to layer $2 / 3$. At E120, presumptive type I $\beta$ A neurons (top, left) have axonal branches in layers $4 C \beta$ and $4 A$ and apical dendritic branches are found in layers $4 A, 4 C \alpha, 4 C \beta$, and 5. By E140 (top, middle), the axonal arbors in layers $4 A$ and $4 C \beta$ have become more extensive, but there are also presumed transient axonal branches in layer $4 C \alpha$, as well as collaterals extending obliquely into layer $4 \mathrm{C} \alpha$. In mature cells (top, right), the exuberant axonal branches and collaterals in layer $4 C \alpha$ have been eliminated. Also, the exuberant dendritic branches observed in layer $4 C \alpha$ at E120 are eliminated before E140. Presumptive type I $\beta$ neurons are not clearly distinguished at E120 and, therefore, might emerge from a morphology that is similar to that of presumptive type I $\beta$ A neurons (top-middle, left). By E140, presumptive type I $\beta$ neurons (top-middle, middle) have dendritic arbors similar to mature type I $\beta$ cells (top-middle, right): their apical dendrites extend only to the top of layer $4 C \beta$ and branch in layer (Figure legend continues.) 
The apical dendrites of both cells were truncated in upper layer $4 \mathrm{C} \beta$ but did have branches in layers $5 \mathrm{~A}$ and $4 \mathrm{C} \beta$.

Four presumptive type $\mathrm{I} \alpha$ and no type Im neurons were labeled at E145. Even at this age, 3 of the 4 neurons displayed immature traits. The one "mature" cell lacked a projection to the white matter, extended its apical dendrite and ascending axons only as high as layer $4 \mathrm{C} \alpha$, and formed apical dendritic and axonal branches only in layer $4 \mathrm{C} \alpha$. The other 3 neurons all projected to the white matter and had axonal branches that extended into layer $4 \mathrm{~B}$, but the incursion into layer $4 \mathrm{~B}$ was minimal for 1 cell (Fig. 12d). Two of these three cells extended their apical dendrite into layer 4B (or higher) and had exuberant dendritic branches in layer $4 \mathrm{~B}$ as well as branches in the correct layers, $4 \mathrm{C} \alpha$ and 5A (Fig. 12d). The last cell also had apical dendritic branches in layers $5 \mathrm{~A}$ and $4 \mathrm{C} \alpha$, but its apical dendrite was truncated at the top of layer $4 \mathrm{C} \alpha$.

\section{DISCUSSION}

Cortical circuits are characterized by connections that are highly layer-specific. Considerable evidence has demonstrated that these layer-specific connections develop precisely, without the formation of incorrect connections (for review, see Katz and Callaway, 1992; Bolz et al., 1996). The present study demonstrates similar specificity in macaque V1. The axons of pyramidal neurons in layers 2-4B, 5 , and 6 select precisely from among the four main cortical layers: 2-4B, 4C, 5, and 6. Previous studies of local circuit development in the visual cortex of other species have demonstrated specificity for the axons from layer $2 / 3$ and layer 6 pyramidal neurons (see, for example, Katz, 1991; Callaway and Lieber, 1996) and layer 4 spiny stellate neurons (Callaway and Katz, 1992), but no previous publications report on layer 5 pyramidal neurons. There is mounting evidence that laminar precision is mediated by cues intrinsic to the cortex, probably molecular markers that are differentially expressed across the cortical layers (Castellani and Bolz, 1997) (for review, see Bolz et al., 1996).

A simple extension of the laminar specificity hypothesis would be that all layer-specific circuits, including those specific for sublayers, develop using the same activity-independent mechanisms. The findings presented here for local circuits in macaque V1 suggest that this is not the case. Although specificity of connections for the main cortical layers is generally precise from the outset, there are several distinct types of laminar imprecision of axonal projections in V1 of prenatal macaque monkeys. These include the following: (1) transient axonal branching in an "incorrect" subdivision of a "correct" layer; (2) axon collaterals that extend into but do not branch in an incorrect layer or sublayer; (3) projections to a layer that is "incorrect" for the type of cell that makes them, but that would not be incorrect for other cell types within the same class; (4) transient axonal branches in the subplate; and (5) transient projections to the white matter (and presumably to extrinsic targets). Summary schematics illustrating possible developmental transitions in laminar organization of axonal arbors of layer $4 \mathrm{C} \beta$ spiny neurons and layer 6, class I pyramidal neurons are illustrated in Figures 14 and 15, respectively. These figures emphasize transient axon collaterals and their elimination from incorrect layers or sublayers for the relevant cell types.

Specific examples of the first type of imprecision are as follows: axonal branches from layer $4 \mathrm{C} \beta$ spiny neurons that are detected in layer 4B; axonal branches of superficial layer 6 pyramidal neurons in layer $4 \mathrm{C} \alpha$; and perhaps axonal branches of presumptive type Im layer 6 neurons in lower layer $4 \mathrm{C} \beta$. The second type of imprecision is also exemplified by layer 6 pyramidal neurons. Most notable are the presumptive type $\mathrm{I} \alpha$ and type Im neurons, whose recurrent ascending axons and axon collateral branches originating in layer $4 \mathrm{C}$ extend into layers $4 \mathrm{~A}$ and $4 \mathrm{~B}$. Branches from type $\mathrm{I} \beta$ and $\mathrm{I} \beta \mathrm{A}$ neurons extending obliquely into layer $4 \mathrm{C} \alpha$ are further examples.

The projections from presumptive type $\mathrm{I} \alpha$ and Im neurons to layers $4 \mathrm{~A}$ and $4 \mathrm{~B}$ are also examples of the third type of imprecision. These projections would be "correct" only if these cells were presumptive type I $\beta$ A neurons. Furthermore, these projections are also examples of the first type of imprecision; projections to the layer 4A subdivision are correct for some layer 6 class I pyramids, but those to layer $4 \mathrm{~B}$ are not correct for any layer 6 , class I cell type.

In addition to laminar specificity, cortical circuits are characterized by highly specific intralaminar connections. Unlike layerspecific connections, these connections are not formed precisely from the outset; they are subject to activity-dependent reorganization (Callaway and Katz, 1990, 1991; Lowel and Singer, 1992; Antonini and Stryker, 1993, 1996; Ruthazer and Stryker, 1996). Apparently, activity-independent cues are available to allow growing axons to distinguish correct target layers, but the numerous functionally distinct neurons within a layer are not distinguished by such cues.

The findings presented here suggest that in the context of this framework, it might be more appropriate to consider at least some sublayer-specific connections to be specific for subsets of neurons within a layer rather than specific for distinct layers. Perhaps the molecular markers that allow growing axons to distinguish between layers are conserved across cortical areas and across species and, therefore, they only distinguish those layers that are common to all cortical areas. It is expected that this question will be better resolved after molecular markers and their receptors have been identified and their expression and homology can be compared across areas and species.

These findings also have implications for the mechanisms that give rise to differences in axonal projections between neurons from the same layer. For example, neurons in the deep cortical layers (layers 5 and 6) fall into two distinct groups: those with recurrent, ascending axon collaterals and those with laterally projecting, local axon collaterals. In prenatal macaque V1, these two populations appear already to be distinct during the elaboration of the first local

$\leftarrow$

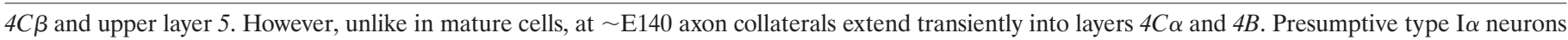

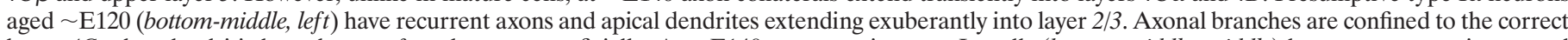

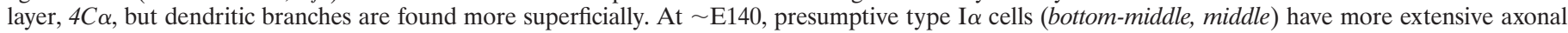

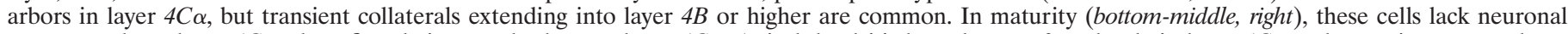

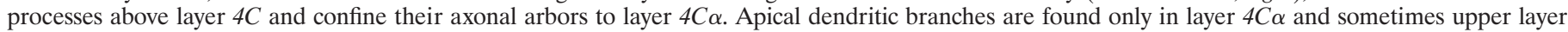

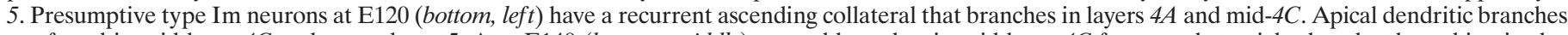

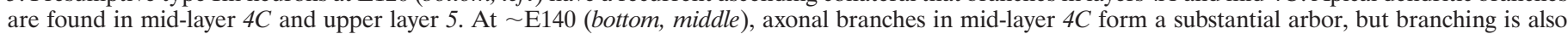

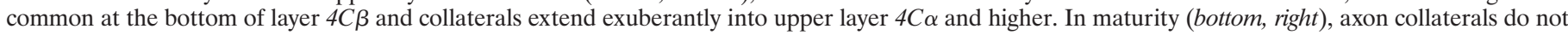
extend above the middle of layer $4 C$, but occasional branches are still found at the bottom of layer $4 C \beta$. Conventions are as in Figure 14 . 
axon collaterals, at E100 and E108. This suggests that the two populations could be genetically distinct, responding differently to the local environment, perhaps because they have a different constellation of receptors for layer-specific molecular markers or because the receptors are coupled to different intracellular signaling pathways. Such a distinction has been hypothesized previously based on the observation that subcortically projecting (presumptive "tall," local, laterally projecting) layer 5 pyramids and callosally projecting (presumptive "short," local, superficially projecting) layer 5 pyramids project precisely to their extrinsic targets. Neurons projecting both callosally and subcortically are not observed (Koester and O'Leary, 1993).

Conversely, class I layer 6 pyramids initially express remarkably similar patterns of local axonal arborization, including extension of exuberant axon collaterals that are not appropriate for a cell's particular presumptive fate, but that would be appropriate for other types of class I pyramids. Specific examples of this include the following: (1) the remarkable similarity between layer 6 pyramids with recurrent axon collaterals at E100-E122; (2) at later ages, recurrent axon collaterals extending to layer $4 \mathrm{~A}$ for presumptive type I $\alpha$ and Im neurons; and (3) axonal branches within layer $4 \mathrm{C} \alpha$ for presumptive type I $\beta$ A neurons. These observations suggest that the different types of layer 6, class I pyramids might emerge from a genetically homogeneous population that is influenced differentially by patterned prenatal activity in the retino-geniculo-cortical network.

The differences in depth at which the various layer 6 cell types are found in mature macaque V1 also suggest this possibility. Parvocellular LGN afferents preferentially target upper layer 6 and layer $4 \mathrm{C} \beta$, and magnocellular afferents target lower layer 6 and layer 4C $\alpha$ (Hubel and Wiesel, 1972; Hendrickson et al., 1978; Blasdel and Lund, 1983). Thus, presumptive type I $\beta$ and I $\beta$ A neurons in upper layer 6 would be influenced little by activity from magnocellular afferents, whereas presumptive $\mathrm{I} \alpha$ and Im neurons in the middle of layer 6 , with basal dendrites extending into lower layer 6, would experience stronger magnocellular influences. The activity of presumptive type $\mathrm{I} \beta$ and I $\beta$ A neurons might then be best correlated with activity in the parvo-recipient layer $4 \mathrm{C} \beta$, whereas activity of presumptive $\mathrm{I} \alpha$ and $\mathrm{Im}$ neurons could be better correlated with the magno-recipient layer $4 \mathrm{C} \alpha$. Developing layer 6 neurons could thereby distinguish between the sublayers in $4 \mathrm{C}$, despite an absence of molecular cues distinguishing those layers. The selective targeting of layer 4A by type $\mathrm{I} \beta \mathrm{A}$ neurons might be mediated similarly by activity driven by the parvocellular input to layer 4A. This hypothesis also can account for the loss of superficial projections by presumptive type $\mathrm{I} \alpha$ and Im neurons, as well as the selective targeting of layer $4 \mathrm{~A}$ versus $4 \mathrm{~B}$ by presumptive type I $\beta$ A neurons.

A previous Golgi study of prenatal neurons in macaque V1 (Lund et al., 1977) concluded that "the characteristic laminar patterns of ... specific axonal and dendritic arborizations seen in the adult are generated in the earliest stages of growth and do not occur as the result of elimination from a wider, less precise, distribution." The findings reported here are in agreement with this conclusion with respect to development of axonal specificity for the four main cortical layers. However, they are not in agreement with respect to the development of sublaminar specificity.

There are many possible reasons for this discrepancy. Most important, it was not known at the time of the Golgi study how the mature axonal arbors of layer 6 pyramidal neurons are organized; nor was it known that different cell types are found only at certain depths within layer 6 . As a result, patterns of axonal arborization that were interpreted to reflect laminar precision of immature Golgi-labeled cells might now be interpreted as exuberant. Another possibility is that the Golgi method does not reliably label axonal arbors.

Axonal branches of prenatal neurons were detected frequently in the subplate. These projections are probably transient, because the subplate is a transient structure and local axonal arbors are not observed in this zone in postnatal animals. Connections between the subplate and the cortical plate are likely to mediate developmental interactions important for the emergence of normal connectivity and functional architecture (for review, see Allendoerfer and Shatz, 1994).

It should be noted that many of the cells with axonal branches in the subplate did not have extensive axonal arbors in this zone. Instead, they sometimes consisted of just one or two branches that extended further into the white matter. Rather than mediating connections with the subplate, such branches could reflect exuberant projections to multiple extrinsic targets.

Like subplate branches, axonal projections to the white matter were far more common in prenatal animals than in maturity. In V1 of postnatal macaque monkeys, a surprisingly small percentage of neurons in deep layers project to the white matter (Fitzpatrick et al., 1994; Callaway and Wiser, 1996; Wiser and Callaway, 1996). Even in layer $2 / 3$, only about half of pyramidal cells are projection neurons (Callaway and Wiser, 1996). In contrast, only 2 of the 54 E100-E108 pyramidal and spiny stellate neurons in layers $2-4 \mathrm{~B}, 5$, and 6 lacked a projection to the white matter. These diminished to mature levels in layer 5 by E122. In layer 6, the decline occurred later, with all of the E122 pyramids projecting to the white matter and a high proportion $(64 \%, 21 / 33)$ still projecting at E135-E145. Finally, in layers 2-4B, all of the spiny neurons still projected to the white matter at E145.

The small percentages of deep layer projection neurons in mature animals place an upper limit on the percentages of cells that could project to the subcortical structures (i.e., superior colliculus, pulvinar nucleus, and LGN) targeted by these neurons (Lund et al., 1975; Hendrickson et al., 1978; Fitzpatrick et al., 1994). These small percentages may reflect the unusually large size of V1 relative to subcortical structures in the macaque monkey (cf. Fitzpatrick et al., 1994). In species in which V1 is relatively smaller, higher percentages of deep layer neurons project to the white matter (see, for example, Martin and Whitteridge, 1984). Thus, the overproduction and later elimination of exuberant white matter projections could reflect a mechanism for matching the extent of projections to the size of the target, much like size matching between a motor neuron pool and a muscle by cell death (for review, see Oppenheim, 1989). The elimination of exuberant projections from V1 might be mediated similarly by activity-dependent competitive influences. However, the large percentage of nonprojecting neurons in mature V1 suggests that most of the size matching in this system is likely to be mediated by process elimination rather than cell death.

In conclusion, the development of local axonal arbors in macaque V1 is highly specific for the main cortical layers from the outset, just as in other species. However, developing neurons do form transient projections to incorrect subdivisions of correct layers. Furthermore, transient projections also can be formed in layers that are incorrect for a particular cell type, as long as the projection would be correct for other cell types within the same class. These observations provide important clues about roles of genetic and environmental influences in specifying laminar and 
sublaminar specificity of axonal arbors as well as in the determination of cell types.

\section{REFERENCES}

Allendoerfer KL, Shatz CJ (1994) The subplate, a transient neocortical structure: its role in the development of connections between thalamus and cortex. Annu Rev Neurosci 17:185-218.

Anderson JC, Martin KAC, Whitteridge D (1993) Form, function, and intracortical projections of neurons in the striate cortex of the monkey Macacus nemestrinus. Cerebral Cortex 3:412-420.

Antonini A, Stryker MP (1993) Development of individual geniculocortical arbors in cat striate cortex and effects of binocular impulse blockade. J Neurosci 13:3549-3573.

Antonini A, Stryker MP (1996) Plasticity of geniculocortical afferents following brief or prolonged monocular occlusion in the cat. J Comp Neurol 369:64-82.

Blakemore C, Molnar Z (1990) Factors involved in the establishment of specific interconnections between thalamus and cerebral cortex. Cold Spring Harb Symp Quant Biol 55:491-504.

Blasdel GG, Lund JS (1983) Termination of afferent axons in macaque striate cortex. J Neurosci 3:1389-1413.

Bolz J, Novak N, Staiger V (1992) Formation of specific afferent connections in organotypic slice cultures from rat visual cortex cocultured with lateral geniculate nucleus. J Neurosci 12:3054-3070.

Bolz J, Castellani V, Mann F, Henke-Fahle S (1996) Specification of layer-specific connections in the developing cortex. Prog Brain Res 108:41-54.

Brodmann K (1909) Vergleichende Lokalisationlehre der Grosshirnrinde in ihren Prinzipien Dargestellt auf Grund des Zellenbaues. Leipzig, Germany: Barth.

Callaway EM (1998) Local circuits in primary visual cortex of the macaque monkey. Annu Rev Neurosci 21:47-74.

Callaway EM, Katz LC (1990) Emergence and refinement of clustered horizontal connections in cat striate cortex. J Neurosci 10:1134-1153.

Callaway EM, Katz LC (1991) Effects of binocular deprivation on the development of clustered horizontal connections in cat striate cortex. Proc Natl Acad Sci USA 88:745-749.

Callaway EM, Katz LC (1992) Development of axonal arbors of layer 4 spiny neurons in cat striate cortex. J Neurosci 12:570-582.

Callaway EM, Lieber JL (1996) Development of axonal arbors of layer 6 pyramidal neurons in ferret primary visual cortex. J Comp Neurol 376:295-305

Callaway EM, Wiser AK (1996) Contributions of individual layer 2-5 spiny neurons to local circuits in macaque primary visual cortex. Vis Neurosci 13:907-922.

Casagrande VA, Kaas JH (1994) The afferent, intrinsic, and efferent connections of primary visual cortex in primates. In: Cerebral cortex Vol 10 (Peters A, Rockland KS, eds), pp 201-259. New York: Plenum.

Castellani V, Bolz J (1997) Membrane-associated molecules regulate the formation of layer-specific cortical circuits. Proc Natl Acad Sci USA 13:7030-7035.

Chagnac-Amitai Y, Luhmann HJ, Prince DA (1990) Burst generating and regular spiking layer 5 pyramidal neurons of rat neocortex have different morphological features. J Comp Neurol 296:598-613.

Conrad S, Ha J, Lohr C, Sackett G (1995) Ultrasound measurement of fetal growth in Macaca nemestrina. Am J Primatol 36:15-35.

Dantzker JD, Callaway EM (1997) Local cues direct the layer-specific development of visual cortical axonal arbors in vitro. Soc Neurosci Abstr 23:306.

Fitzpatrick D, Usrey WM, Schofield BR, Einstein G (1994) The sublaminar organization of corticogeniculate neurons in layer 6 of macaque striate cortex. Vis Neurosci 11:307-315.

Gilbert CD, Wiesel TN (1979) Morphology and intracortical projections of functionally characterized neurones in the cat visual cortex. Nature 280:120-125.

Gilbert CD, Wiesel TN (1983) Clustered intrinsic connections in cat visual cortex. J Neurosci 3:1116-1133

Gilbert CD, Wiesel TN (1989) Columnar specificity of intrinsic horizontal and cortical connections in cat visual cortex. J Neurosci 9:2432-2442.

Hassler R (1967) Comparative anatomy of the central visual systems in day- and night-active primates. In: Evolution of the forebrain (Hassler R, Stephen S, eds), pp 419-434. Stuttgart, Germany: Thieme.

Hendrickson AE, Wilson JR, Ogren MP (1978) The neuroanatomical organization of pathways between the dorsal lateral geniculate nucleus and visual cortex in Old World and New World primates. J Comp Neurol 182:123-136.

Horton JC (1984) Cytochrome oxidase patches: a new cytoarchitectonic feature of monkey visual cortex. Phil Trans R Soc Lond [Biol] 304:199-253.

Hubel DH, Wiesel TN (1972) Laminar and columnar distribution of geniculo-cortical fibers in the macaque monkey. J Comp Neurol 146:421-450.

Katz LC (1991) Specificity in the development of vertical connections in cat striate cortex. Eur J Neurosci 3:1-9.

Katz LC, Callaway EM (1992) Development of local circuits in mammalian visual cortex. Annu Rev Neurosci 15:31-56.

Katz LC, Gilbert CD, Wiesel TN (1989) Local circuits and ocular dominance columns in monkey striate cortex. J Neurosci 9:1389-1399.

Kennedy H, Bullier J, Dehay C (1985) Cytochrome oxidase activity in the striate cortex and lateral geniculate nucleus of the newborn and adult macaque monkey. Exp Brain Res 61:204-209.

Koester SE, O'Leary DD (1993) Connectional distinction between callosal and subcortically projecting cortical neurons is determined prior to axon extension. Dev Biol 160:1-14.

Le Vay S, Connolly M, Houde J, Van Essen DC (1985) The complete pattern of ocular dominance stripes in the striate cortex and visual field of the macaque monkey. J Neurosci 5:486-501.

Lowel S, Singer W (1992) Selection of intrinsic horizontal connections in the visual cortex by correlated neuronal activity. Science 255:209-212.

Lund JS (1988) Anatomical organization of macaque monkey striate visual cortex. Annu Rev Neurosci 11:253-288.

Lund JS, Boothe RG (1975) Interlaminar connections and pyramidal neuron organisation in the visual cortex, area 17 , of the macaque monkey. J Comp Neurol 159:305-334.

Lund JS, Lund RD, Hendrickson AE, Bunt AH, Fuchs AF (1975) The origin of efferent pathways from the primary visual cortex, area 17, of the macaque monkey as shown by retrograde transport of horseradish peroxidase. J Comp Neurol 164:287-303.

Lund JS, Boothe RG, Lund RD (1977) Development of neurons in the visual cortex of the monkey (Macaca nemestrina): a Golgi study from fetal day 127 to postnatal maturity. J Comp Neurol 176:149-188.

Malach R, Amir Y, Harel M, Grinvald A (1993) Relationship between intrinsic connections and functional architecture revealed by optical imaging and in vivo targeted biocytin injections in primate striate cortex. Proc Natl Acad Sci USA 90:10469-10473.

Martin KAC, Whitteridge D (1984) Form, function and intracortical projections of spiny neurons in the striate cortex of the cat. J Physiol (Lond) 353:463-504.

Oppenheim RW (1989) The neurotrophic theory and naturally occurring motoneuron death. Trends Neurosci 7:252-255.

Peinado A, Katz LC (1990) Development of cortical spiny stellate cells: retraction of a transient apical dendrite. Soc Neurosci Abstr 16:1127.

Rockland KS, Lund JS (1983) Intrinsic laminar lattice connections in primate visual cortex. J Comp Neurol 216:303-318.

Ruthazer ES, Stryker MP (1996) The role of activity in the development of long-range horizontal connections in area 17 of the ferret. J Neurosci 16:7253-7269.

Tarantal AF, Hendrickx AG (1988) Prenatal growth in the cynomolgus and rhesus macaque (Macaca fascicularis and Macaca mulatta): a comparison by ultrasonography. Am J Primatol 15:309-323.

Valverde $\mathrm{F}$ (1985) The organizing principles of the primary visual cortex in the monkey. In: Cerebral cortex, Vol 3 (Peters A, Jones EG, eds), pp 207-257. New York: Plenum.

Wiesel TN, Hubel DH, Lam DMK (1974) Autoradiographic demonstration of ocular dominance columns in the monkey striate cortex by means of transneuronal transport. Brain Res 79:273-279.

Wiser AK, Callaway EM (1996) Contributions of individual layer 6 pyramidal neurons to local circuitry in macaque primary visual cortex. J Neurosci 16:2724-2739.

Wiser AK, Callaway EM (1997) Ocular dominance columns and local projections of layer 6 pyramidal neurons in macaque primary visual cortex. Vis Neurosci 14:241-251.

Yamamoto N, Kurotani T, Toyama K (1989) Neural connections between the lateral geniculate nucleus and visual cortex in vitro. Science 245:192-194.

Yoshioka T, Blasdel GG, Levitt JB, Lund JS (1996) Relation between patterns of intrinsic lateral connectivity, ocular dominance, and cytochrome oxidase-reactive regions in macaque monkey striate cortex. Cerebral Cortex 6:297-310. 